Document downloaded from:

http://hdl.handle.net/10251/100072

This paper must be cited as:

Tsoncheva, T.; Issa, G.; Blasco Lanzuela, T.; Dimitrov, M.; Popova, M.; Hernández Morejudo, S.; Kovacheva, D... (2013). Catalytic VOCs elimination over copper and cerium oxide modified mesoporous SBA-15 silica. Applied Catalysis A General. 453:1-12. doi:10.1016/j.apcata.2012.12.007

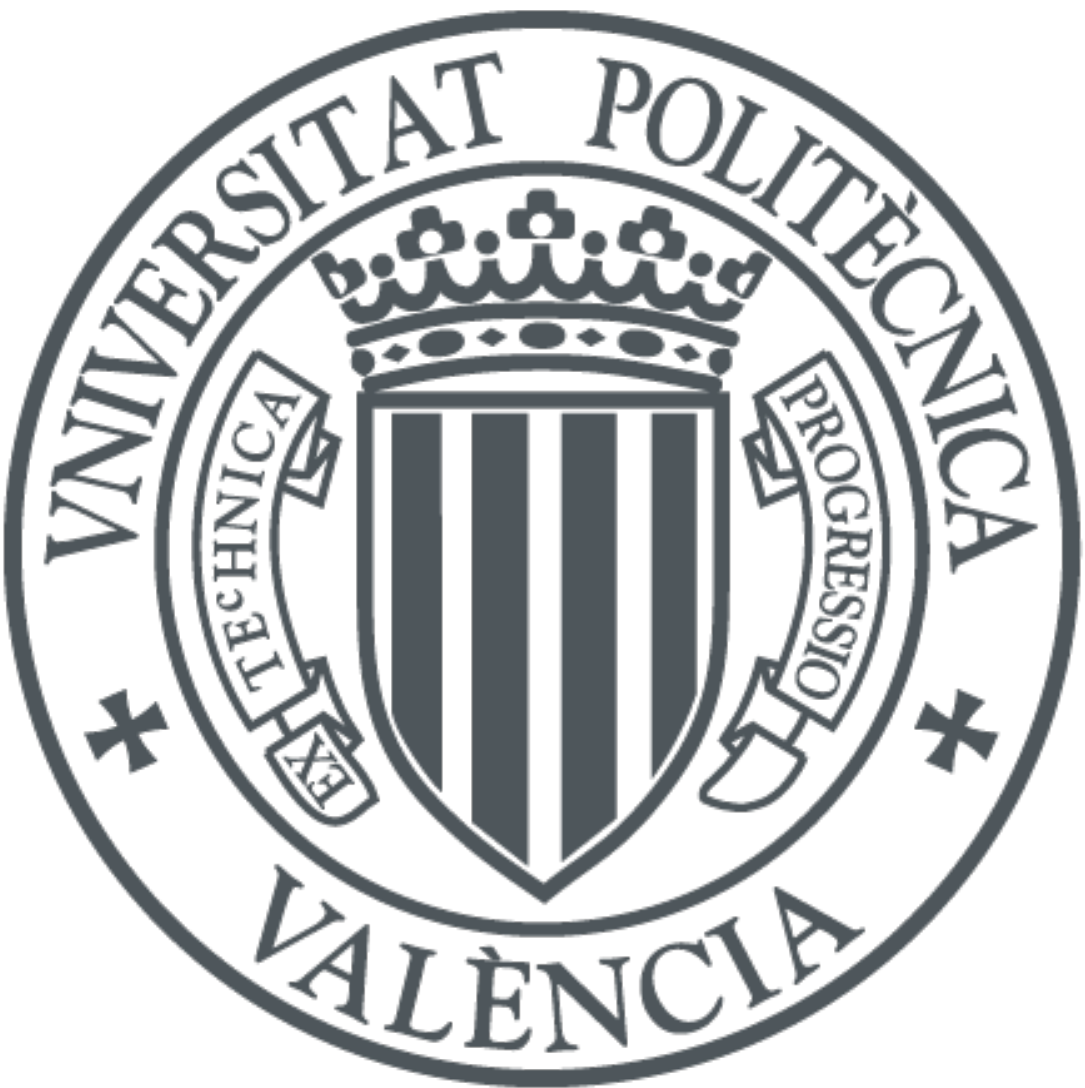

The final publication is available at

https://doi.org/10.1016/j.apcata.2012.12.007

Copyright Elsevier

Additional Information 


\title{
Catalytic VOCs elimination over copper and cerium oxide modified mesoporous SBA-15 silica
}

Tanya Tsoncheva ${ }^{a}$, Gloria Issa ${ }^{a}$, Teresa Blasco ${ }^{\mathrm{b}}$, Momtchil Dimitrov $^{\mathrm{a}}$, Margarita Popova ${ }^{\mathrm{a}}$, Selene Hernández ${ }^{\mathrm{b}}$, Daniela Kovacheva ${ }^{\mathrm{c}}$, Genoveva Atanasova ${ }^{\mathrm{c}}$, José M. López Nieto ${ }^{\mathrm{b}}$

${ }^{a}$ Institute of Organic Chemistry with Centre of Phytochemistry, Bulgarian Academy of Sciences, Sofia, Bulgaria, e-mail:tsoncheva@orgchm.bas.bg, tel.+029796640

${ }^{b}$ Instituto de Tecnologia Química (UPV-CSIC), Campus Universidad Politécnica Valencia, 46022-Valencia, Spain

${ }^{c}$ Institute of General and Inorganic Chemistry, Bulgarian Academy of Sciences, Acad. G. Bonchev St., Block 13, 1113 Sofia, Bulgaria.

\begin{abstract}
Copper and cerium oxide bi-component materials with different $\mathrm{Cu} / \mathrm{Ce}$ ratio were prepared using ordered SBA-15 silica as a support and compared with their bulk analogues. The samples were characterized by nitrogen physisorption, XRD, UV-Vis, FTIR, XPS, Raman spectroscopy and TPR with hydrogen. Cyclohexanol conversion was used as a catalytic test to obtain more information for the surface properties of the supported materials. The catalytic properties of the samples were studied in VOCs oxidation using toluene and ethyl acetate as probe molecules. A strong effect of silica support and samples composition on the formation of catalytic sites was established.
\end{abstract}

\section{Key words}

VOCs oxidation, copper and cerium oxide catalysts, SBA-15 support, catalytic sites 


\section{Introduction}

Volatile organic compounds (VOCs) emitted from various industrial processes and transport activities are considered as an important class of air pollutants, and now they are a subject of strict legislation. In the last decades, many technologies have been devoted for the abatement of VOCs emissions. Among them, the catalytic total oxidation has been recognized as more economical process for VOCs elimination even in low concentrations, reducing also the level of toxic by-products emission in a high extent [1-4]. Transition metal oxide catalysts offer much technical and commercial advantage that make them a viable alternative to noble metals $[5-11]$.

Recently, copper cerium oxide binary system have been intensively studied in various reactions, such as combustion of $\mathrm{CO}$ and methane [1, 12-15], $\mathrm{SO}_{2}$ reduction [16], hydrogen production by steam reforming of methanol [17, 18], reduction of NO [19], decomposition of $\mathrm{H}_{2} \mathrm{O}_{2}$ [20], wet oxidation of phenol [21] etc. It was demonstrated higher catalytic activity of copper cerium mixed oxides than precious metals for preference $\mathrm{CO}$ oxidation in excess of hydrogen (CO-PROX) $[12,22-25]$ as well as excellent activity in water gas shift reaction (WGSR) at low temperature [26-29]. To date, these materials are also used as additives in the three way catalysts for purification of automobile exhaust gas in order to reduce the cost of noble metals [30 and refs. therein]. The superior catalytic activity of this binary system in different reactions has been a subject of intensive investigation and controversial conclusions. Generally, a synergism of the redox properties of both metal oxides is assumed and it is assigned to strong interaction between $\mathrm{CuO}$ and $\mathrm{CeO}_{2}$, which causes part of $\mathrm{CuO}$ to enter in ceria lattice, forming solid solution, and other part to disperse over the surface [25,31-34]. Some authors related the catalytic behaviour of copper modified ceria with the creation of additional surface oxygen vacancies $[35,36]$ and assumed that the dispersion and exposure of 
nanosized copper particles in close contact with ceria vacancies play an essential role for WGSR at low temperature $[28,37,38]$. The other authors considered that finely dispersed $\mathrm{CuO}$ are the main active sites in $\mathrm{CO}$ oxidation and the larger bulk $\mathrm{CuO}$ nanoparticles possess a little contribution in the catalytic reaction [39]. Alternatively, the stabilization of $\mathrm{Cu}^{+}$ions due to the strong interaction between copper oxide clusters and ceria and their activity in $\mathrm{CO}$ oxidation was reported [25]. Martinez-Arias et al. [23] claimed that the facile redox interplay between cerium and copper is a key factor of high catalytic activity of these binary samples. Boaro et al. [40] related the highest activity of the interface between both metal oxide phases to intensive mobility of surface oxygen and changes in the redox state of both copper and cerium phases. Recently Dziembaj [41] assumed that the mobility of oxygen and the electron transfer within the bulk of ceria must be also taken into consideration during the oxidation reactions.

Although copper-cerium catalysts have been considered as effective oxidation catalysts, their performance in VOCs oxidation has been scarcely studied. Delimaris [1] and $\mathrm{Hu}$ [3] investigated the catalytic performance of copper ceria binary oxides in acetone, ethanol, ethyl acetate and toluene combustion. They demonstrated an optimum in copper content to achieve excellent catalytic activity in ethanol and ethyl acetate combustion, while no significant effect of copper addition to ceria was observed at low temperatures for toluene oxidation. The authors concluded that the active sites that are responsible for $\mathrm{CO}$ oxidation did not operate under the conditions of VOCs oxidation due to the complexity of reaction pathway for the latter materials and the increase of the catalytic activity was considered as a result of specific surface area increase in binary system as compared to the corresponding single metal oxides. $\mathrm{Hu}[42,43]$ related the higher activity of copper cerium catalysts in acetone oxidation to the formation of highly dispersed copper oxide particles, but they did not exclude the positive effect of $\mathrm{Cu}^{+}$ions as well. Saqer et al. [44] assumed that the large $\mathrm{CuO}$ crystallites did not 
contribute significantly to the catalytic activity of supported on alumina copper ceria binary oxides in toluene oxidation. They reported that the improved performance of mixed binary oxide materials is not due to the formation of solid solution or new mixed oxide system, but due to facile spreading of metal oxides over each other [44].

Despite the copper ceria catalysts have been intensively studied, most of investigations were focused on their behaviour in bulk, non-supported form, where copper oxide was doped with ceria or vice versa. It was found that the intimate contact between different metal oxide particles depends on the amount of both components as well as on the preparation method and the activation procedures used [30]. The behaviour of these materials, when they were loaded on various supports was studied in much lower extent [4, 30, 45]. Rao [32] reported higher interaction between different oxide species, which provided higher activity in CO oxidation, when they were supported on $\mathrm{SiO}_{2}$ and $\mathrm{ZrO}_{2}$ support as compared to the $\mathrm{Al}_{2} \mathrm{O}_{3}$ support.

Ordered mesoporous silicas have been assumed as suitable catalysts support because mesopores provide large specific surface area and porous volume for achievement high metal/metal oxides loading. During last two decades, the success in the synthesis of mesoporous silicas resulted in preparation of large family of mesoporous silicas with tunable pore size, shape and topology, which opened new prospects for the fabrication of stable, well dispersed, and uniform metal/metal oxide nanoparticles via their hosting into the mesoporous matrix [46]. However, to the best of our knowledge, negligible data for the simultaneous hosting of copper and cerium oxide species on mesoporous silica supports were published $[45]$.

The aim of present paper is to study a series of binary copper and cerium oxide materials with different composition, supported on mesoporous SBA-15 silica. The effect of porosity on the state of loaded metal oxide nanoparticles was studied using a complex of various physicochemical techniques, such as XRD, Nitrogen physisorption, TPR with hydrogen, 
FTIR, UV-Vis and XPS spectroscopy as well as cyclohexanol conversion as a catalytic test. In order to study the nature of the loaded species, the supported copper ceria materials were compared with their bulk analogues. They were obtained by co-precipitation technique, since it has been considered as the preferment method for synthesis of copper doped ceria with good intimate contact between different particles [22, 30, 35, 47]. The obtained binary metal oxide materials were studied as potential catalysts for total oxidation of different VOCs pollutants. Ethyl acetate and toluene were chosen as model compounds due to their hazardous nature and extensive use as solvents and feedstock in printing, pressing, petro chemistry and other industries.

\section{Experimental}

\subsection{Materials}

SBA-15 mesoporous silica was prepared according to the procedure described in [48] using Pluronic 123 triblock-co-polymer $\left(\mathrm{EO}_{20} \mathrm{PO}_{70} \mathrm{EO}_{20}\right)$ as structure-directing agent and TEOS (Aldrih) as a siliceous source. The hydrothermal synthesis was performed at $368 \mathrm{~K}$ and the template was released by calcinations in air at $773 \mathrm{~K}$ for 6 hours. Copper and cerium modifications were prepared by incipient wetness impregnation of mesoporous silica with aqueous solutions of $\mathrm{Cu}\left(\mathrm{NO}_{3}\right)_{2} \cdot 2 \mathrm{H}_{2} \mathrm{O}$ or $\mathrm{Ce}\left(\mathrm{NO}_{3}\right)_{3} \cdot 6 \mathrm{H}_{2} \mathrm{O}$ for the mono-component materials $(\mathrm{Cu} / \mathrm{SBA}-15$ and $\mathrm{Ce} / \mathrm{SBA}-15$, respectively), or with a mixture of both precursors in appropriate ratio, for the bi-component ones. The nitrate precursors were decomposed after pre-treatment in air at $773 \mathrm{~K}$ for $2 \mathrm{~h}$. The total metal content in all modifications was $6 \mathrm{wt} \%$. In the case of bi-component materials, the $\mathrm{Cu} / \mathrm{Ce}$ weight ratio changed as $2 / 4,3 / 3$ and $4 / 2$ for the $2 \mathrm{Cu} 4 \mathrm{Ce} / \mathrm{SBA}-15,3 \mathrm{Cu} 3 \mathrm{Ce} / \mathrm{SBA}-15$ and $4 \mathrm{Cu} 2 \mathrm{Ce} / \mathrm{SBA}-15$ samples, respectively. For comparison, mono- and selected bi-component bulk analogues of these materials were obtained by precipitation of an aqueous solution of the corresponding salts, i.e $\mathrm{Ce}$ - and $\mathrm{Cu}$ - 
nitrates, with $\mathrm{KOH}(2 \mathrm{M})$, filtered, dried at $373 \mathrm{~K}$ and calcined at $773 \mathrm{~K}$ for $2 \mathrm{~h}$. The samples were denoted as $\mathrm{CuO}$ and $\mathrm{CeO}_{2}$, for the mono-component materials and $2 \mathrm{Cu} 4 \mathrm{Ce}$ and $4 \mathrm{Cu} 2 \mathrm{Ce}$, for the bi-component ones with $\mathrm{Cu} / \mathrm{Ce}$ weight ratio of $2 / 4$ and $4 / 2$, respectively.

\subsection{Methods of investigation}

Nitrogen physisorption data were obtained by multi-point $\mathrm{N}_{2}$ adsorption at $77 \mathrm{~K}$, in a Micromeritics ASAP 2000 instrument. Powder X-ray diffraction patterns were collected within the range of 5.3 to $80^{\circ} 2 \theta$ with a constant step $0.02^{\circ} 2 \theta$ on Bruker D8 Advance diffractometer with $\mathrm{Cu} \mathrm{K}_{\alpha}$ radiation and LynxEye detector. Low-angle part of the patterns was collected from 0.3 to $8^{\circ} 2 \theta$ using the knife-edge anti-scatter screen attachment of the primary beam. Phase identification was performed with the Diffracplus EVA using ICDD-PDF2 Database. The average metal oxide crystallite size was evaluated from the diffraction peaks broadening at $28.5^{0} 2 \theta$ for ceria and $35.4^{0} 2 \theta$ for copper oxide, respectively, according the Scherrer equation. The IR spectra (KBr pellets) were recorded on a Bruker Vector 22 FTIR spectrometer at a resolution of $1-2 \mathrm{~cm}^{-1}$, accumulating $64-128$ scans. The UV-Vis spectra were recorded on the powder samples using a Jasco V-650 UV-Vis spectrophotometer equipped with a diffuse reflectance unit. The XPS measurements were done in the UHV chamber of ESCALAB- Mk II (VG Scientific) electron spectrometer with a base pressure of $1.10^{-8} \mathrm{~Pa}$. The photoelectron spectra were excited using unmonochromatized Al $\mathrm{K} \alpha_{1,2}$ radiation $(\mathrm{h} v=1486.6 \mathrm{eV})$. The composition and chemical surrounding of samples were investigated on the basis of the areas and binding energies of $\mathrm{Cu} 2 \mathrm{p}_{3 / 2}, \mathrm{Ce} 3 \mathrm{~d}$ and $\mathrm{Si} 2 \mathrm{p}$ photoelectron peaks and Scofield's photoionization cross-sections. Raman spectra were recorded in ambient conditions using a Renishaw system 1000 "in via” attached to a microscope. An argon ion laser (532-nm) was used as the excitation source and was typically operated at a power of $20 \mathrm{~mW}$. 
The TPR/TG (temperature-programmed reduction/ thermogravimetric) analyses were performed in a Setaram TG92 instrument. Typically, $40 \mathrm{mg}$ of the sample were placed in a microbalance crucible and heated in a flow of $50 \mathrm{vol} \% \mathrm{H}_{2}$ in $\mathrm{Ar}\left(100 \mathrm{~cm}^{3} \mathrm{~min}^{-1}\right)$ up to $773 \mathrm{~K}$ at $5 \mathrm{~K} \mathrm{~min}^{-1}$ and a final hold-up of $1 \mathrm{~h}$. The weight loss during the reduction was calculated on the base of TPR-TG curves and the values were normalized to one and the same catalyst weight (40 mg).

\subsection{Catalytic experiments}

The catalytic oxidation of ethyl acetate was performed in a flow type reactor $(0.100 \mathrm{~g}$ of catalyst) with a mixture of ethyl acetate in air (1.21 mol \%) and WHSV of $100 \mathrm{~h}^{-1}$. Before the catalytic experiments the samples were pre treated in argon at $373 \mathrm{~K}$ for $1 \mathrm{~h}$. The catalytic experiments were performed with a stepwise temperature increase with steady state measurements at every temperature per $1 \mathrm{~h}$. Gas chromatography analyses were done on a HP 5890 apparatus using carbon-based calibration. The products distribution was calculated as $\mathrm{CO}_{2}\left(\mathrm{~S}_{\mathrm{CO} 2}\right)$, acetaldehyde $\left(\mathrm{S}_{\mathrm{AA}}\right)$, ethanol $\left(\mathrm{S}_{\mathrm{Et}}\right)$ and acetic acid $\left(\mathrm{S}_{\mathrm{AcA}}\right)$ selectivity by the equation: $\mathrm{Si}=\mathrm{X}_{\mathrm{i}} / \mathrm{X}_{\text {total }} * 100$, where $\mathrm{Si}$ and $\mathrm{Xi}$ are the selectivity and the yield of (i) product and $\mathrm{X}_{\text {tot }}$ is the conversion. The specific activity (SA) was calculated as the current conversion value per 1 specific surface area.

Toluene oxidation was studied in a flow reactor using air as carrier gas at toluene partial pressure of $0.9 \mathrm{kPa}$ and WHSV-1.2 $\mathrm{h}^{-1}$. On-line gas chromatographic analysis were performed on HP 5980 with PLOT Q column using detector of thermo conductivity. The catalytic activity was studied in temperature programmed regime. The selectivity of $\mathrm{CO}_{2}$ $\left(\mathrm{S}_{\mathrm{CO} 2}\right)$ was calculated as $\mathrm{Si}=\mathrm{X}_{\mathrm{CO} 2} / \mathrm{X}_{\text {total }} * 100$. The samples were tested also in steady state regime under isothermal conditions $(630 \mathrm{~K})$. 
Cyclohexanol conversion was carried out in a flow reactor, using nitrogen as carrier gas and nitrogen to cyclohexanol molar ratio of 38 . The activity was determined at $523 \mathrm{~K}$ after the samples pre-treatment in air at $373 \mathrm{~K}$ or reduced in hydrogen at $523 \mathrm{~K}$ for $2 \mathrm{~h}$. On-line analysis of the reaction products was performed using HP-GC with a $30 \mathrm{~m}$ HP-35 capillary column. The results were presented as selectivity of cyclohexene and cyclohexanone, calculated as a ratio between the current yields of the corresponding products and total conversion $(\%)$ at the selected temperature.

\section{Results and Discussion}

\subsection{Catalytic properties in VOCs oxidation}

\subsubsection{Ethyl acetate oxidation}

The catalytic properties of copper and cerium oxide non-supported (bulk) and supported on SBA-15 materials in oxidation of ethyl acetate as a probe molecule of oxygen containing VOCs are presented in Figs. 1, 8. All catalysts exhibit catalytic activity above $530 \mathrm{~K}$ (Figs. 1a,2a) and carbon dioxide, ethanol, acetaldehyde and acetic acid with different selectivity are registered as products from the combustion (Supplementary data, Figure S1). Cu/SBA-15 demonstrates relatively low conversion degree (below $20 \%$ ) in the whole investigated temperature interval, while the non-supported $\mathrm{CuO}$ reveals much higher catalytic activity with the temperature increase above $600 \mathrm{~K}$. Both ceria materials show significantly higher catalytic activity even at relatively low temperatures and again, it is better for the bulk analogue. Among the bulk bi-component catalysts, $4 \mathrm{Cu} 2 \mathrm{Ce}$ sample exhibits higher catalytic activity and $\mathrm{CO}_{2}$ selectivity than the mono-component ones, while they are extremely low for $2 \mathrm{Cu} 4 \mathrm{Ce}$

(Fig. 1). Such a strong dependence of the samples composition is not observed for the supported bi-component analogues (Fig. 2). Here, the best activity is found for $2 \mathrm{Cu} 4 \mathrm{Ce} / \mathrm{SBA}$ 15, while the other bi-component samples are more active only than $\mathrm{Cu} / \mathrm{SBA}-15$. All catalysts 
demonstrate relatively stable catalytic behaviour with time on stream at $630 \mathrm{~K}$ (Figs.1c,d and $2 \mathrm{c}, \mathrm{d})$.

\subsubsection{Toluene oxidation}

Catalytic properties of all supported on SBA-15 silica materials in total oxidation of toluene, as a probe molecule of aromatic VOCs are presented in Fig. 3. $\mathrm{CO}_{2}$ is observed as the main product in the whole investigated temperature interval (Fig. 3b), but in some cases, benzaldehyde is also registered as a by-product. All bi-component samples exhibit higher catalytic activity in comparison with the mono-component ones, but at lower temperature, they demonstrate higher ability for by-products formation. Note that $\mathrm{Cu} / \mathrm{SBA}-15$ exhibits extremely fast deactivation with time on stream, while the activity of bi-component samples remains relatively stable at $630 \mathrm{~K}$ (Fig. 3c,d).

\subsection{Catalysts characterization}

\subsubsection{Nitrogen physisorption}

In order to obtain information for the textural characteristics of the studied materials, nitrogen physisorption measurements are done. The isotherms of parent SBA-15 and its metal oxide modifications (supplementary data, Fig. S2) are of IV type with H1 hysteresis loop and sharp capillary condensation step in the range of $0.5-0.8 \mathrm{P} / \mathrm{P}_{0}$, typical of mesoporous materials with uniform cylindrical pores and average pore diameter about 5.4-5.8 $\mathrm{nm}$ [48]. The similarity in the isotherms after the metal oxides loading reveals the preservation of support pore structure during the modification procedure. The observed decrease in the BET surface area and pore volume for the modified materials in comparison with the parent silica (Table 1) could be due to the location of metal oxide nanoparticles within the porous structure. This effect is more pronounced for $2 \mathrm{Cu} 4 \mathrm{Ce} / \mathrm{SBA}-15$, where a slight decrease in the pore diameter is also 
observed. The observed simultaneous decrease of the microporous volume and BET surface area for this sample does not exclude also partial location of metal oxide particles within the support micropores. The change in the shape of desorption branch for the samples with high ceria content (supplementary data, Fig. S2), combined with significant decrease in the mesoporous volume, could be due to partial pore blocking with ceria particles [49].

In the case of bulk materials, the specific surface area (Table 1) for $\mathrm{CeO}_{2}$ is about 20 times higher than for $\mathrm{CuO}$. A decrease of BET surface area is observed after ceria modification with copper. This effect is more pronounced for the sample with lower copper content $(2 \mathrm{Cu} 4 \mathrm{Ce})$, which indicates that the obtained bi-component bulk materials are not a physical mixture of $\mathrm{CuO}$ and $\mathrm{CeO}_{2}$ oxides.

\subsubsection{Powder X-ray diffraction}

Small-angle X-ray diffraction patterns of parent SBA-15 silica and its modifications (supplementary data, Fig. S3) represent intensive well-resolved signals, which could be indexed as (100), (110) and (200) reflections of well organized 2-D hexagonal lattice with p6 $\mathrm{mm}$ symmetry [48]. These results are in accordance with the nitrogen physisorption data that indicate preservation of support structure during the modification procedure.

In the wide angle region of Ce/SBA-15 pattern (Fig 4a), the broad reflections at $2 \theta=28.5^{0}$, $33.1^{0}, 47.5^{0}, 56.3^{0}$ and $69.4^{0}$ demonstrate presence of small ceria crystallites (Table 1), which in accordance with the nitrogen physisorption data (See Section 3.2.1), are predominantly located within the mesopores of the support. The sharp diffraction peaks in the $\mathrm{Cu} / \mathrm{SBA}-15$ sample at $2 \theta=35.4^{0}, 38.9^{0}, 48.6^{0}, 58.3^{0}, 61.4^{0}, 66.1^{0}$ and $68.1^{0}$ are due to the presence of highly crystalline $\mathrm{CuO}$ phase. The average crystallite diameter is larger than the porous diameter of the support (Table 1), indicating $\mathrm{CuO}$ particles location on the outer surface. In all bi-component materials the reflections of ceria are not well resolved, and no reflections of 
copper oxide phase are registered for $2 \mathrm{Cu} 4 \mathrm{Ce} / \mathrm{SBA}-15$, as well. This evidences the presence of finely dispersed metal oxide particles, probably located into the pore structure (Table 1). At the same time, partial segregation of $\mathrm{CuO}$ phase on the outer surface of the silica support is assumed for the bi-component materials with higher copper content (Table1, Fig. 4a).

For the bulk bi-component materials, formation of more finely dispersed metal oxide particles in comparison with pure metal oxides is observed (Fig.4b, Table 1). For the former materials, a slight increase of the ceria unit cell parameter is also registered (Table 1). However, the observed results are insufficient to assume correctly the formation of solid solution. According to [38], the substitution of large $\mathrm{Ce}^{4+}$ ion $(0.97 \mathrm{~nm})$ by smaller $\mathrm{Cu}^{2+}$ ion $(0.73 \mathrm{~nm})$ is expected to contract the ceria cell, while the concomitant formation of oxygen vacancies provide the opposite effect and the combination of both factors results in preservation of unit cell parameters to a high extent.

\subsubsection{FTIR and UV-Vis spectra}

In order to obtain more information for the state of various metal oxide species, FTIR and UV-Vis spectra are recorded. FTIR spectra of all parent and modified SBA-15 silica materials consist of intense bands at around 1080, 800 and $450 \mathrm{~cm}^{-1}$ (supplementary data, Fig. S4), which are typical of the characteristic symmetric and asymmetric vibrations in $\mathrm{Si}-\mathrm{O}-\mathrm{Si}$ bridges in silicas [50]. The band around $1600 \mathrm{~cm}^{-1}$ is due to the adsorbed water molecules [51]. The broad band in the interval $3100-3700 \mathrm{~cm}^{-1}$ is assigned to $\mathrm{O}-\mathrm{H}$ stretching vibrations. The additional bands in the $600-400 \mathrm{~cm}^{-1}$ region, which are well resolved in the spectra of $\mathrm{Cu} / \mathrm{SBA}-15$, can be assigned to the presence of $\mathrm{CuO}$ crystallites [52]. However, these bands are in a high extent masked by the intensive bands of the silica matrix and we can not observe them for samples with lower copper content. The interpretation of the band around $960 \mathrm{~cm}^{-1}$ is more complicated and generally it is assigned to $\mathrm{Si}-\mathrm{O}$ stretching vibrations in defect $\mathrm{Si}-\mathrm{O}-\mathrm{M}$ 
structures, where $M$ is hydrogen or metal ion [53]. Despite the controversial interpretation of this band [53-56], the observed significant changes in its profile only for $\mathrm{Cu} / \mathrm{SBA}-15$ (supplementary data, Fig. S4), could be carefully assigned to the existence of strong interaction between copper species and support silanol groups. This interaction seems to decrease for bi-component materials, probably due to the creation of new contact between both metal oxide nanoparticles.

The diffuse reflectance UV- Vis spectra are further recorded, since this technique is very sensitive to obtain more information for the environment of metal ions (Fig. 5). The bands at 343 and $313 \mathrm{~nm}$, which are registered in the spectra of $\mathrm{CeO}_{2}$ and $\mathrm{Ce} / \mathrm{SBA}-15$ samples, respectively, correspond to $\mathrm{O}^{2-} \rightarrow \mathrm{Ce}^{4+} \mathrm{CT}$ transitions [57]. As was reported in [58], its position depends on the ligand field symmetry around the cerium center. In accordance with the XRD data (See Section 3.2.2), the observed shift of the bands for both materials is due to the formation of smaller ceria particles after their deposition on SBA-15 [59]. The band at 250 $\mathrm{nm}$ could be due to the $\mathrm{O}^{2-} \rightarrow \mathrm{Ce}^{3+} \mathrm{CT}$ transitions, which implies the occurrence of oxygen vacancy defects $[60,61]$. The absorption in the range of $240-320 \mathrm{~nm}$ and $600-800 \mathrm{~nm}$ regions for $\mathrm{CuO}$ and $\mathrm{Cu} / \mathrm{SBA}-15$ is related to $\mathrm{O}^{2-} \rightarrow \mathrm{Cu}^{2+} \mathrm{CT}$ and $\mathrm{d}-\mathrm{d}$ transitions, respectively, of crystalline $\mathrm{CuO}$ [57]. The position of the peak at around $240 \mathrm{~nm}$ is slightly blue shifted for $\mathrm{Cu} / \mathrm{SBA}-15$, which is probably due to the presence of more finely dispersed $\mathrm{CuO}$ crystallites [62]. The spectra of all bi-component materials represent higher absorption in the 300-550 nm region (Fig. 5). This could be assigned to higher particles dispersion and appearance of strong interaction between them. According to [24], the increase absorption in this region did not exclude the formation of $\mathrm{Cu}^{+}$ions. The interpretation of the band at about $250 \mathrm{~nm}$, which is generally assigned to $\mathrm{Ce}^{3+}$ ions, is also quite complicated due to its overlapping with the typical bands of $\mathrm{CuO}$ in this range. 


\subsubsection{Raman spectroscopy}

In order to obtain more information for the type of interaction between metal oxide nanoparticles, Raman spectra are obtained (Fig. 6). The spectrum of the $\mathrm{CuO}$ sample (Fig. 6a) represents three main peaks at 275, 330 and $619 \mathrm{~cm}^{-1}$, typical of $\mathrm{CuO}$ phase [63]. The spectrum of $\mathrm{CeO}_{2}$ consists of intensive peak at ca. $463 \mathrm{~cm}^{-1}$, which is assigned to $\mathrm{F} 2 \mathrm{~g}$ mode of $\mathrm{CeO}_{2}$ fluorite structure $[18,43,64,65]$. A slight red shift of the position of this band, combined with significant decrease in its intensity with a simultaneous increase of the halfwidth is observed for $2 \mathrm{Cu} 4 \mathrm{Cu}$ (Fig. 6a). At the same time the disappearance of the main $\mathrm{CuO}$ peaks and a significant increase of the relative intensity of the peak around $600 \mathrm{~cm}^{-1}$ is observed. Generally, the latter feature is assigned to the formation of oxygen vacancies due to the replacement of $\mathrm{Ce}^{4+}$ by metal ion with different valence $[36,63,66,67]$.

The Raman spectrum of pure SBA-15 silica support represented the main peaks at around $500,604,810$ and $960 \mathrm{~cm}^{-1}$, which could be assigned to the vibrations of three and four silane rings, siloxane linkage and defect sites, such as silanol groups (Fig. 6b) [68]. The main Raman peak of ceria in Ce/SBA-15 (Fig. 6b) becomes broader, more asymmetric and about $10 \mathrm{~cm}^{-1}$ red shifted in comparison with bulk $\mathrm{CeO}_{2}$. In accordance with the XRD data this is due to the formation of more finely dispersed ceria nanoparticles within the porous silica structure [66]. The main peaks of copper oxide are well resolved in the spectrum of $\mathrm{Cu} / \mathrm{SBA}-15$, which supported XRD data for the formation of well crystallized $\mathrm{CuO}$ nanoparticles. Note the increased intensity of the band around $960 \mathrm{~cm}^{-1}$ for $\mathrm{Cu} / \mathrm{SBA}-15$ in comparison with the parent silica. In accordance with the FTIR and UV -Vis data, we assign this feature to the presence of finely dispersed copper oxide species, which are in strong interaction with surface silanol groups. This high intensity band is still present in the spectrum of $2 \mathrm{Cu} 4 \mathrm{Ce} / \mathrm{SBA}-15$, while the bands which are typical of $\mathrm{CuO}$ phase fully disappear. In accordance with the UV-Vis data 
(Fig.5b), we assume the influence of ceria for the formation of finely dispersed copper containing species, which are in strong interaction with the support.

\subsubsection{XPS spectra}

More information for the concentration and oxidative state of different metal ions on the catalyst surface is obtained by XPS measurements. The core level Cu2 $p_{3 / 2}$ spectra (Fig. 7a) demonstrate shake-up peaks at 940-945 eV and main peak centered at ca. $932.8 \mathrm{eV}$. The main $\mathrm{Cu} 2 \mathrm{p}_{3 / 2}$ peak for $2 \mathrm{Cu} 4 \mathrm{Ce} / \mathrm{SBA}-15$ is shifted to higher $\mathrm{BE}(933.2 \mathrm{eV})$, which in accordance with the XRD data (see above), is due to higher dispersion of $\mathrm{CuO}$ in this sample $[63,69]$. The asymmetry of the main $\mathrm{Cu} 2 \mathrm{p}_{3 / 2}$ peak to higher $\mathrm{BE}$, could be also due to the formation of $\mathrm{Cu}$ O-Si surface structures [69]. Generally, the presence of shake-up peak and the higher values of $\mathrm{Cu} 2 \mathrm{p}_{3 / 2} \mathrm{BE}(933.0-933.8 \mathrm{eV})$ is reported as two major characteristics of $\mathrm{Cu}^{2+}$ ions, while lower $\mathrm{Cu} 2 \mathrm{p}_{3 / 2} \mathrm{BE}(932.2-933.0 \mathrm{eV})$ and the absence of shake-up peak are characteristic for reduced copper species $[6,70,71]$. It is difficult to distinguish $\mathrm{Cu}^{+}$and $\mathrm{Cu}^{0}$ on the base of $\mathrm{Cu}$ $2 \mathrm{p}_{3 / 2}$ peaks alone, because they have essentially the same BE. That's why the copper LMM Auger lines are also recorded (Fig. 7b). The broad features, which are shifted to lower kinetic energy for the bi-component materials, could be assigned to the presence of $\mathrm{Cu}^{+}$ions. The presence of $\mathrm{Cu}^{+}$ions in copper cerium oxide binary systems, obtained by various methods, was also observed by number of authors [43,71-74]. Maluf et al. [66] proposed that these reduced copper ions could result from the strong interaction between $\mathrm{CuO}$ clusters and $\mathrm{CeO}_{2}$, where the formation of $\mathrm{Cu}^{+}$might be induced at the interface by the substitution of the two oxide phases, because $\mathrm{Ce}^{4+}$ and $\mathrm{Cu}^{+}$have similar radii [3 and refs. therein].

Ce3d core level spectra are shown in Fig. 7c. The core level signals are broad due to the contribution of several peaks, which could be assigned to $\mathrm{Ce}^{4+}$ ions $[33,72,73]$. The bands at ca. 903.2 and $884-886 \mathrm{eV}$, which are related to $\mathrm{Ce}^{3+}$ ions [70], are also observed. Thus the 
concomitant reduction of copper and cerium oxides provides an evidence for the synergistic activity between them [69].

The surface concentrations of $\mathrm{Cu}, \mathrm{Ce}$ and $\mathrm{Si}$ are presented in Table 2. The observed tendency for all bi-component materials for the enrichment of the surface with copper could be related to the increase in its dispersion when it is in a close contact with ceria species [43]. We could assume location of finely dispersed copper oxide species onto the ceria surface and $\mathrm{Cu}^{+}$ions, incorporated into the ceria lattice.

\subsubsection{TPR-TG measurements}

In order to study the nature of metal oxide species in detail, TPR measurements are carried out. This method is known as a powerful approach to obtain more information for the environment of metal ions and it could be a key to understand the catalytic behaviour of materials in various redox processes. Many studies demonstrate that the synergistic effect between $\mathrm{CuO}$ and $\mathrm{CeO}_{2}$ is evident from the decrease in the reduction temperature of both $\mathrm{CuO}$ and $\mathrm{CeO}_{2}$ oxides. However, we should note that the interpretation of the results from the TPR analyses could be rather complicated, especially for the supported binary materials, where interaction of different metal oxide species with the support and in-between is expected. That's why the data reported in the literature on the interpretation of the reduction profiles of copper-cerium oxides are rather controversial. Rao [74] observes the appearance of two reduction peaks, centered at 418 and $443 \mathrm{~K}$, which are assigned to the reduction of $\mathrm{CuO}$ particles with different dispersion on ceria. Alternatively, these features are assigned to the step-wise reduction of $\mathrm{CuO}[43,75]$. Two reduction maxima are observed also by Liu [18], the first one, whose intensity and position is not significantly varied with copper loading, is attributed to copper ions or $\mathrm{CuO}$ clusters in close interaction with ceria. Moreover, the main peak, whose intensity increases with copper loading, is attributed to the reduction of bulk-like 
$\mathrm{CuO}$. These authors reveal that the position of the first peak is representative for the strength of copper cerium interaction. $\mathrm{Hu}$ [43] and $\mathrm{Si}$ [38] assume that highly dispersed copper clusters or isolated ions, which are in strong interaction with the support, could be reduced at relatively high temperatures. Zheng [63] registered three reduction steps, assigned to the reduction of highly dispersed copper species, strongly interacted with ceria and to the larger $\mathrm{CuO}$ particles, less associated with ceria, respectively. Ramaswamy [24] also observed three reduction effects with maxima at around 420, 500 and $700 \mathrm{~K}$, which are ascribed to the reduction of finely dispersed $\mathrm{CuO}$ species in close contact with ceria, bulk $\mathrm{CuO}$ or clusters loosely bonded to ceria, and reduction of ceria, which is facilitated by the presence of copper. Avgouropoulos [76] observed four reduction effects, which are assigned to the reduction of non crystalline $\mathrm{CuO}$ species, strongly interacted with ceria, larger $\mathrm{CuO}$ particles weakly interacted with ceria and bulk $\mathrm{CuO}$ particles, respectively.

TPR- TG and TPR-DTG profiles of all studied SBA-15 supported materials are presented in Figs. 8,a,b. In order to understand the TPR effects better, data for their bulk analogues are also obtained (Figs. 5,c,d). Some TPR parameters are also listed in Table 3. The bulk CuO sample exhibits a strong weight loss effect (Fig. 5,c,d) above $433 \mathrm{~K}$ with a maximum at about $471 \mathrm{~K}$, which corresponds to total one step reduction of $\mathrm{Cu}^{2+}$ to metallic copper (Table 3). For the supported Cu/SBA-15 (Figs.8, a,b), the position of the main reduction peak is almost similar to that one of the bulk material, but the peak is asymmetric to higher temperatures and additional weight loss above $660 \mathrm{~K}$ is observed. Taking into account the lower reduction degree (about $85 \%$ ) for this material in comparison with its bulk analogue and in accordance with the XRD, FTIR, Raman and UV-Vis data, we assume the formation of copper species with different dispersion on silica support, part of them being in strong interaction with the support silanol groups. According to [77-80], a step wise $\mathrm{Cu}^{2+} \rightarrow \mathrm{Cu}^{+} \rightarrow \mathrm{Cu}^{0}$ reduction with partial stabilization of $\mathrm{Cu}^{+}$ions on the silica surface is not excluded for the smaller species. 
The reduction of both mono-component ceria materials starts above $660 \mathrm{~K}$. The total reduction degree of $\mathrm{Ce}^{4+} \rightarrow \mathrm{Ce}^{3+}$ transition is about 3 times higher for the supported material, despite in both cases, it remains significantly low, probably due to the reduction transformations of cerium ions predominantly from the surface [83].

The TPR profiles of bi-component bulk materials (Fig. 8,c,d) are broader in comparison with the mono-component bulk $\mathrm{CuO}$ and they are shifted to lower temperatures for the sample with higher $\mathrm{Cu} / \mathrm{Ce}$ ratio. We should also stress on the significantly lower reduction degree for binary bulk materials than the expected theoretical one (Table 3). We assigne these features to the reduction of different copper containing species in these samples. In accordance with XRD, UV-Vis, XPS and Raman data, the copper particles, which are easily reducible in the sample $4 \mathrm{Cu} 2 \mathrm{Ce}$, are most probably finely dispersed $\mathrm{CuO}$ crystallites, stabilized on the ceria surface. The copper ions, which are hardly reducible, are probably into the bulk of ceria lattice, which are dominant in the sample with lower $\mathrm{Cu} / \mathrm{Ce}$ ratio $(2 \mathrm{Cu} 4 \mathrm{Ce})$.

All binary supported systems reduce at lower temperatures than $\mathrm{Cu} / \mathrm{SBA}-15$ and behaved like 4Cu2Ce bulk sample (Fig. 8,a,b). So, the main TG effect in them, which generally occurs above $370 \mathrm{~K}$ with a maximum in DTG curves at around $460 \mathrm{~K}$, is probably due to the reduction of well crystallized and finely dispersed $\mathrm{CuO}$ crystallites. Note, the continuous weight loss in the higher temperature interval $(500-700 \mathrm{~K})$ in the TG profiles for all bicomponent SBA-15 supported samples, which is not observed for $\mathrm{Cu} / \mathrm{SBA}-15$ and also for the bi-component bulk materials. In accordance with Raman, UV-Vis, FTIR and XPS measurements, we assign these features to the reduction transformations of 2-dimensional $\mathrm{Cu}$ $\mathrm{O}-\mathrm{Cu}$ structures, stabilized by interaction both with ceria and silica matrix.

\subsubsection{Cyclohexanol conversion as a catalytic test.}


More information for the surface properties of the supported on SBA-15 metal oxide species is obtained using cyclohexanol conversion as a catalytic test (Fig. 9). It is well known the flexibility of this molecule to dehydrate to cyclohexene in presence of catalytic acidic sites or to dehydrogenate to cyclohexanone on the redox sites. In our experiment, the selectivity to cyclohexene and cyclohexanone is compared at $503 \mathrm{~K}$, where the conversion degree over all materials is almost similar (about $20 \%$ ). For all modified materials, cyclohexene is the major product, indicating the presence of acidic sites (Fig. 9a). The acidic function is higher for all bi-component materials in comparison with their mono-component analogues. After the reduction of the samples at $523 \mathrm{~K}$ (Fig. 9b), a significant decrease of acidity is assumed for the samples with relatively high copper content (Cu/SBA-15 and 4Cu2Ce/SBA-15). Note, that under this reduction treatment, the acidity of pure ceria materials remains almost unchanged. So, the changes in the selectivity can be related to the specific activity of copper species in the samples. As was reported previously [77, 80], the Lewis acidity of copper oxide species could be related to low coordinated metal ions, which present in finely dispersed metal oxide structures. In accordance with the Raman and TPR data (see above), we expect that most of these species are stabilized by the silica silanol groups, and as a result, they are hardly reducible. Taking into account the TPR data, we assume that their relative contribution is higher for all bi-component materials (Fig. 8, a,b), and this well correlates with the increased cyclohexanol dehydration activity of these samples. The catalytic behaviour of the samples after the reduction treatment reveals that the stabilization of copper species strongly depends on the copper content. We assume that the relative part of hardly reducible copper ions, which are stabilized into the ceria structure, is higher for the samples with lower $\mathrm{Cu} / \mathrm{Ce}$ ratio.

So, the physisorption analyses with different techniques (See Section 3) indicate that the porous SBA-15 support promotes the formation of more finely dispersed ceria particles in comparison with the non-supported material and they are mostly located into the mesopores 
of the host matrix. However, the copper phase in supported mono-component material is more non-homogeneously dispersed and it is located both on the outer surface and inside the support pores, including the micropores. The XRD, Uv-Vis, Raman and TPR measurements reveal that the ceria crystallite size significantly decreases after doping with copper, and in the case of non-supported materials, this effect is more pronounced with the copper content increase. FTIR, UV-Vis and catalytic test with cyclohexanol indicate appearance of specific interaction between different metal oxide particles in bi-component materials. For the nonsupported oxides, this interaction leads to changes in the specific surface area (See nitrogen physisorption data). For the supported materials, it provides the formation of finely dispersed copper species in interaction both with ceria and silica. TPR analyses reveal a significant decrease in the reduction degree for the bulk bi-component materials as compared to the mono-component ones, which indicates strong interaction between different metal oxide particles. This effect is regulated by the $\mathrm{Cu} / \mathrm{Ce}$ ratio and is higher for the sample with lower copper content. At the same time the overall reducibility of supported materials does not change significantly with samples composition and remains close to the reduction degree for $\mathrm{Cu} / \mathrm{SBA}-15$. The observed shift in the initial reduction temperature and the specificity of the TPR profiles indicate the formation of different copper species in the bi-component materials. XRD, Raman and XPS spectra do not exclude partial incorporation of copper (mainly $\mathrm{Cu}^{1+}$ ) ions into the ceria lattice with a creation of oxygen vacancies in it. Such penetration of copper ions into the ceria lattice is much pronounced for the bulk samples, obtained by coprecipitation method, especially at low $\mathrm{Cu} / \mathrm{Ce}$ ratio. The Raman and TPR data show that the degree of penetration of copper ions into the lattice decreases for the supported materials, probably due to the existence of additional interaction of the metal species with the silica support. The formation of finely dispersed $\mathrm{CuO}$ crystallites onto the ceria ones as well as twodimensional $\mathrm{O}-\mathrm{Cu}-\mathrm{O}$ structures, which are in interaction both with ceria and surface silanol 
groups, is facilitated in this case. Moreover, the pore structure seems to restrict the contact between the particles. Here a segregation of bulk copper oxide particles is also possible on the outer surface for the materials with higher $\mathrm{Cu} / \mathrm{Ce}$.

The change in the state of metal oxide particles both by the influence of $\mathrm{Cu} / \mathrm{Ce}$ ratio and by their deposition on silica support strongly affects their catalytic behaviour. We calculated theoretic catalytic activity for the bulk materials in ethyl acetate combustion at $600 \mathrm{~K}$, considering them as a physical mixture of both oxides. It was $65 \%$ and $54 \%$ for $2 \mathrm{Cu} 4 \mathrm{Ce}$ and $4 \mathrm{Cu} 2 \mathrm{Ce}$, respectively, while the real experimental values are about 31 and $90 \%$, respectively. Note, that the specific surface area for $2 \mathrm{Cu} 4 \mathrm{Ce}$ is lower than for $4 \mathrm{Cu} 2 \mathrm{Ce}$ (Table 1). In order to ignore this effect, we also calculated the specific activity (SA) for both samples as conversion per a unit catalyst surface. And it was about twice lower for $2 \mathrm{Cu} 4 \mathrm{Ce}$ than for $4 \mathrm{Cu} 2 \mathrm{Ce}$. Taking into account also the results from physicochemical analysis, we consider that the penetration of copper ions into the ceria lattice leads to the creation of less active catalytic sites in 2Cu4Ce. We'd like to stress that among the non-supported materials, the lowest catalytic activity of this sample well correlates with its lowest reducibility. This result could be easily understood, taking into account that the ethyl acetate combustion on metal oxides generally occurred via Mars van Krevelen mechanism, where the release of lattice oxygen is of primary importance [1]. As was already mentioned, the silica support decreases the penetration of copper ions into the ceria lattice both by the creation of simple barrier of pore structure or by the existence of additional interaction with the surface silanol groups. At the same time more finely dispersed $\mathrm{CuO}$ particles, which are probably in close contact with ceria or with the silica support are formed. They are easily reducible and depending on their accessibility into the 2D-pore matrix for the reactants, they could increase the catalytic activity. Indeed, the observed conversion for all supported bi-component materials is about 1.5-2 times higher than the expected theoretic one if they were simple mechanical mixture of the corresponding 
mono-component samples. The specific effect of porous silica support is also evident from the reverse effect of $\mathrm{Cu} / \mathrm{Ce}$ ratio on the catalytic properties for the supported and bulk materials. We also demonstrate the highest catalytic activity and stability for bi-component materials in toluene oxidation. $\mathrm{Hu}$ [3] proposed a mechanism, where the adsorption of oxygen and toluene on the catalysts surface is considered as a step of key importance. In our study the data from the cyclohexanol catalytic test evidence presence of significant amount of copper species in highly unsaturated state (Fig. 9), which are stable even under reduction conditions. In accordance with the proposed mechanism [3] we assume the participation of these species as strong and stabile adsorption sites during the toluene oxidation.

We do not exclude also changes with the catalysts by the influence of the reaction medium. FTIR spectra (Supplementary data, Fig. S5) for the samples after the catalytic test showed the accumulation of carbon containing products on the surface. The XRD patterns of the used in the catalytic test samples pointed to re-dispersion of metal oxide phase and to the formation of reduced copper species like $\mathrm{Cu}_{2} \mathrm{O}$ and metallic copper (Fig. 4). Such reduction transformations with copper oxide are also reported in [82]. This effect is especially well pronounced during the toluene oxidation, where they reflect on the strong decrease in the activity of $\mathrm{Cu} / \mathrm{SBA}-15$.

\section{Conclusion}

Ceria doping with small amount of copper by co-precipitation of nitrate precursors leads to significant incorporation of copper ions into the ceria lattice, which decreases their reducibility and catalytic activity in VOCs oxidation. The increase in the $\mathrm{Cu} / \mathrm{Ce}$ ratio for these materials promotes the segregation of finely dispersed and easily reducible copper oxide crystallites. These particles are stabilized, being in close contact with ceria and exhibits high activity and selectivity in total oxidation of VOCs. The copper interaction with ceria 
significantly changes after the metal oxides deposition on SBA-15 mesoporous silica. The silica support controls the mode of interaction between the loaded metal oxide particles via regulation of their dispersion and location into the porous structure, as well as via interaction between metal oxide species and surface silanol groups. At low $\mathrm{Cu} / \mathrm{Ce}$ ratio, the interaction between different metal oxide species realizes predominantly into the mesopores of the silica host matrix with the formation of finely dispersed cerium and copper oxide structures. The interaction of copper species with surface silanol groups decreases the degree of copper ions penetration into the ceria lattice, which improves their reducibility and catalytic activity. The increase in the $\mathrm{Cu} / \mathrm{Ce}$ ratio leads to partial deposition of bulk copper oxide particles on the outer silica surface, which restricts the contact with ceria. These particles contribute to a lower extent to overall catalytic activity, particularly due to the decrease of the accessibility to the active sites via partial pore blocking. The optimization of the samples composition and porous topology of the support seems to be a powerful factor for the preparation of highly active and selective copper and ceria bi-component catalysts and further investigation is in progress.

\section{Acknowledgements}

Financial support of Bulgarian Academy of Science and National Scientific Fond of Ministry of Education Projects DTK 02/64 and ДНТС/Китай 01/8, financial support from DGICYT in Spain (Project CTQ-2009-14495) and bilateral project Bulgarian-Spain Inter-academic Exchange Agreement (Project 2009BG0002) are acknowledged.

\section{References}

[1] D. Delimaris, T. Ioannides, Appl. Catal. B: Environmental 89 (2009) 295-302.

[2] P. Papaefthimiou, T. Ioannides, X.E. Verykios, Appl. Therm. Eng. 18 (1998) 1005-1012. 
[3] C. Hu, Chem. Eng. J. 168 (2011) 1185-1192.

[4] P. M. Heynderickx, J. W. Thybaut, H. Poelman, D. Poelman, G. B. Marin, J. Catal. 272 (2010) 109-120.

[5] I. Maupin, J. Mijoin, J. Barbier, N. Bion, T. Belin, P. Magnoux, Catal. Today 176 (2011) 103-109.

[6] M.C. Álvarez-Galván, V.A. de la Pena O’Shea, G. Arzamendi, B. Pawelec, L.M.

Gandía, J.L.G. Fierro, Appl. Catal. B: Environmental 92 (2009) 445-453.

[7] M. Raciulete, P. Afanasiev, Appl. Catal. A: General 368 (2009) 79-86.

[8] B. Puertolas, B. Solsona, S. Agrura,m R. Murillo, A. M. Mastral, A. Aranda, S.H. Taylor, T. Garcia, Appl. Catal. B:Environmental 93 (2010) 395-405.

[9] W.B. Li, J.X. Wang, H. Gong, Catal. Today 148 (2009) 81-87.

[10] F.G. Durán, B.P. Barbero, L.E. Cadús, C. Rojas, M.A. Centeno, J.A. Odriozola, Appl. Catal. B: Environmental 92 (2009) 194-201.

[11] D. Delimaris, T. Ioannides, Appl. Catal. B: Environmental 84 (2008) 303-312.

[12] G. Avgouropoulos, T. Ioannides, Appl. Catal. A: General. 244 (2003) 155-167.

[13] W. Liu, M. Flytzani-Stephanopoulos, J. Catal. 153 (1995) 317-332.

[14] A. C. Ferreira, A.M. Ferraria, A.M. B. Rego, A. P. Goncalves, A. V. Girão, R. Correia, T. A. Gasche, J. B. Branco, J. Mol. Catal. A: Chemical 320 (2010) 47-55.

[15] F. Mariño, C. Descorme, D. Duprez, Appl. Catal. B: Environmental 58 (2005)175-183. [16] A. Tschöpe, W. Liu, M. Flytzani-Stephanopoulos, J.Y. Ying, J. Catal. 157 (1995) 42-50. [17] J. Papavasiliou, G. Avgouropoulos, T. Ioannides, Appl. Catal. B: Environmental 69 (2007) 226-234.

[18] Y. Liu, T. Hayakawa, K. Suzuki, S. Hamakawa, T. Tsunoda, T. Ishii, M. Kumagai, Appl. Catal. A: General 223 (2002) 137-145.

[19] N. A. S. Amin, E. F. Tan, Z. A.Manan, Appl. Catal. B:Environmental 43 (2003) 57-69. 
[20] G.R. Rao, H.R. Sahu, B.G. Mishra, Colloid Surf. A 220 (2003) 261-269.

[21] S. Hocevar, U. Opara Krašovec, B. Orel, A.S. Aricó, H. Kim, Appl. Catal. B:

Environmental 28 (2000) 113-125.

[22] J. L. Ayastuy, A. Gurbani, M. P. Gonzalez-Marcos, M. A. Gutierrez-Ortiz, Int. J.

Hydrogen Energy, 35 (2010) 1232 -1244.

[23] A. Martinez-Arias, A.B. Hungria, G. Munuera, D. Gamarra, Appl. Catal. B:

Environmental 65 (2006) 207-216.

[24] V. Ramaswamy, S. Malwadkar, S. Chilukuri, Appl. Catal. B: Environmental 84 (2008) $21-29$.

[25] T. Caputo, L. Lisi, R. Pirone, G. Russo, Appl. Catal. A: General 348 (2008) 42-53; and refs. therein.

[26] L.Q.Fu, M. Flytzani-Stephanopoulos, Appl. Catal. B : Environmental 27 (2000) 179_ 191.

[27] H. Kušar, S. Hocevar, J. Levec, Appl. Catal. B: Environmental 63 (2006) 194-200.

[28] T. Tabakova, F. Boccuzzi, M. Manzoli, J.W. Sobczak, V. Idakiev, D. Andreeva, Appl. Catal. A: General 298 (2006) 127-143.

[29] F. Huber, Z. Yu, J.C. Walmsley, D. Chen, H.J. Venvik, A. Holmen, Appl. Catal. B: Environmental 71 (2007) 7-15.

[30] R. Prasad, G. Rattan, Bull. Chem. React. Eng. Catal., 5 (2010) 7 - 30; and refs. therein

[31] N. F.P. Ribeiro, M. M.V.M. Souza, M. Schmal, J. Power Sources 179 (2008) 329-334.

[32] K. N. Rao, P. Bharali, G. Thrimurthulu, B. M. Reddy, Catal. Commun. 11 (2010) 863866.

[33] H. Wan, D. Li, Y. Dai, Y. Hu, Y. Zhang, L. Liu, B. Zhao, B. Liu, K. Sun, L. Dong, Y. Chen, Appl. Catal. A: General 360 (2009) 26-32.

[34] H. Chen, H. Zhu, Y. Wu, F. Gao, L. Dong, J. Zhu, J. Mol. Catal. A: Chem. 255 (2006) 
$254-259$.

[35] P. Bera, K.R. Priolkar, P.R. Sarode, M.S. Hegde, S. Emura, R. Kumashiro,

N.P. Lalla, Chem. Mater. 14 (2002) 3591-3601.

[36] X. Wang, J.A. Rodriguez, J.C. Hanson, D. Gamarra, A. Martínez-Arías, M. FernándezGarcía, J. Phys. Chem. B 109 (2005) 19595-19603.

[37] X. Wang, J.A. Rodriguez, J.C. Hanson, D. Gamarra, A. Martínez-Arías,M. FernándezGarcía, J. Phys. Chem. B 110 (2006) 428-434.

[38] R. Si, J. Raitano, N. Yia, L. Zhang, S.-W. Chan, M. Flytzani-Stephanopoulos, Catal. Today 180 (2012) 68-80; and refs therein.

[39] J. Xiaoyuan, I. Guanglie, Z. Renxian, M. Jianxin, C. Yu, Z. Xiaoming,. Appl. Surf. Sci. $173(2001) 208-220$.

[40] M. Boaro, M. Vicario, C. de Leitenburg, G. Dolcetti, A. Trovarelli, Catal. Today 77 (2003) 407-417.

[41] R. Dziembaj, M. Molenda, L. Chmielarz, M.M. Zaitz, Z. Piwowarska, A. RafalskaŁasocha, Catal. Today 169 (2011) 112-117.

[42] C. Hu, Q. Zhu, Z. Jiang, L. Chen, R.Wu, Chem. Eng. J. 152 (2009) 583-590.

[43] C. Hu, Chem. Eng. J. 159 (2010) 129-137.

[44] S. M. Saqer, D. I. Kondarides, X. E. Verykios, Appl. Catal. B: Environmental 103 (2011) $275-286$.

[45] C. Y. Wang, H. Bai, Catal. Today 174 (2011) 70-78.

[46] A. Taguchi, F. Schüth, Micropor. Mesopor. Mater. 77 (2005) 1-45.

[47] Y. Zhang, S. Andersson, M. Muhammed, Appl. Catal. B 6 (1995) 325-337.

[48] M. Choi, W. Heo, F. Kleitz, R. Ryoo, Chem. Commun. (2003) 1340-1341.

[48] P. I. Ravikovitch, A.V. Neimark, Langmuir 18 (2002) 9830-9837.

[50] S. Zheng, L. Gao, J. Gao, Mater. Chem. Phys. 71 (2001)174-178. 
[51] M. Selvarej, A. Pandurangan, K.S. Seshadri, Appl. Catal. A: General 242 (2003) 347354.

[52] L.S. Wang, J.C. Deng, F. Yang, T. Chen, Mater. Chem. Phys. 108 (2008) 165-169.

[53] N. Brodie-Linder, R. Besse, F. Audonnet, S. LeCaer, J. Deschamps, M.Impéror-Clerc, C. Alba-Simionesco, Micropor. Mesopor. Mater. 132 (2010) 518-525.

[54] C-H. Tu, A.-Q. Wang, M.-Y. Zheng, X.-D. Wang, T. Zhang, Appl. Catal. A: General 297 (2006) 40-47.

[55] A. Yin, X. Guo, W. Dai, H. Li, K. Fan, Appl. Catal. A: General 349 (2008) 91-99.

[56] R. Takahashi, S. Sato, T. Sodesawa, M. Kawakita, K. Ogura, J. Phys. Chem. B 104 (2000) 12184-12191.

[57] H. Praliaud, S. Mikhailenko, Z. Chajar, M. Primet, Appl. Catal. B: Environmental 16 (1998) 359-374.

[58] S.C. Laha, P. Mukherjee, S.R. Sainkar, R. Kumar, J. Catal. 207 (2002) 213-223.

[59] B.M. Reddy, P. Bharali, P. Saikia, S.-E. Park, M.W.E. van den Berg, M. Muhler, W.

Grünert, J. Phys. Chem. C 112 (2008) 11729-11737.

[60] B.M. Reddy, K.N. Rao, P. Bharali, Ind. Eng. Chem. Res. 48 (2009) 8478-8486.

[61] L. Liu, Y. Chen, L. Dong, J. Zhu, H. Wan, B. Liu, B. Zhao, H. Zhu, K. Sun, L. Dong, Y.

Chen, Appl. Catal. B: Environ. 90 (2009) 105-114.

[62] K. Chary, G. Sagar, C. Srikanth, V.Rao, J. Phys. Chem. B 111 (2007) 543-550.

[63] X.-C. Zheng, S.-H. Wu, S.-P. Wang,S.-R. Wang, S.-M. Zhang, W.-P. Huang, Appl.

Catal. A: General 283 (2005) 217-223.

[64] W.H. Weber, K.C. Hass, J.R. McBride, Phys. Rev. B 48 (1993) 178-185.

[65] G. Aguila, F. Gracia, P. Araya, Appl.Catal. A: General 343 (2008) 16-24.

[66] W. Shan, W. Shen, C. Li, Chem. Mater. 15 (2003) 4761-4767. 
[67] J.E. Spanier, R.D. Robinson, F. Zhang, S.-W. Chan, I.P. Herman, Phys. Rev. B 64 (2001) $245407-245414$.

[68] J. Liu, L. Yu, Z. Zhao, Y. Chen, P. Zhu, C. Wang, Y. Luo, C. Xu, A. Duan, G. Jiang, J. Catal. 285 (2012) 134-144; and refs. therein.

[69] J. Zhu, Q. Gao, Z. Chen, Appl. Catal. B: Environmental 81 (2008) 236-243.

[70] C.D.Wagner,W.M. Riggs, L.E. Davis, J.F.Moulder, G.E. Muilenberg, Handbook of X-Ray Photoelectron Spectroscopy, Perkin-Elmer Corp., Palo Alto, CA, 1978.

[71] S.S. Maluf, P.A.P. Nascente, E.M. Assaf, Fuel Proc. Technol. 91 (2010) 1438-1445.

[72] F. Zhao, S. Ji, P. Wu, Z. Li, C. Li, Catal. Today 147S (2009) S215-S219.

[73] Á. Reyes-Carmona, A. Arango-Díaz, E. Moretti, A. Talon, L. Storaro, M. Lenarda, A. Jiménez-López, E. Rodríguez-Castellón, J. Power Sources 196 (2011) 4382-4387.

[74] G. Rao, H. Sahu, B. Mishra, Colloids Surf. A 220 (2003) 261-269.

[75] Z. Shanghong, B. Xue, W. Xiaoyan, Y Wenguo, L.Yuan, J. Rare Earths 24 (2006) 177 181.

[76] G. Avgouropoulos, T. Ioannides, H. Matralis, Appl. Catal. B: Environmental 56 (2005) 87-93.

[77] L. Chmielarz, P. Kustrowski, R. Dziembaj, P. Cool, E.F. Vansant, Appl.Catal. B:

Environmental 62 (2006) 369-380.

[78] X.-Y. Hao, Y.-Q. Zhang, J.-W. Wang, W. Zhou,C. Zhang, S. Liu, Micropor. Mesopor. Mater. 88 (2006) 38-47.

[79] D. An, Q. Zhang, Y. Wang, Catal. Today 157 (2010) 143-148.

[80] L. Chmielarz, P. Kustrowski, R. Dziembaj, P. Cool, E.F. Vansant, Micropor. Mesopor. Mater. 127 (2010) 133-141.

[81] G. Rao, B. G. Mishra, Bull. Catal. Soc. India 2 (2003)122-134.

[82] G. Marban, A. B. Fuertes, Appl. Catal. B: Environmental 57 (2005) 43-53. 


\section{Figure captions:}

Figure 1. Evolution of ethyl acetate conversion (a, c) and $\mathrm{CO}_{2}$ selectivity (b, d) with reaction temperature (up) or with time on stream at $630 \mathrm{~K}$ (down) for various bulk modifications.

Figure 2. Evolution of ethyl acetate conversion ( $\mathrm{a}, \mathrm{c})$ and $\mathrm{CO}_{2}$ selectivity $(\mathrm{b}$, d) with reaction temperature (up) or with time on stream at $630 \mathrm{~K}$ (down) for various SBA-15 modifications.

Figure 3. Evolution of toluene conversion $(\mathrm{a}, \mathrm{c})$ and $\mathrm{CO}_{2}$ selectivity $(\mathrm{b}, \mathrm{d})$ with reaction temperature (up) or with time on stream at $630 \mathrm{~K}$ (down) for various SBA-15 modifications. Figure 4. XRD patterns of SBA-15 modifications and bulk material before $(\mathrm{a}, \mathrm{b})$ and after catalytic test in ethyl acetate oxidation $(c, d)$.

Figure 5. UV- Vis spectra for copper and cerium oxide bulk (a) and supported on SBA-15 silica (b) materials.

Figure 6. Raman spectra of selected copper and cerium oxide bulk (a) and SBA-15 supported (b) materials.

Figure 7. Cu2 $\mathrm{p}_{3 / 2}$ (a), CuLMM (b) and Ce3d (c) XPS spectra of selected copper and cerium oxide modified SBA-15.

Figure 8. TPR-TG and TPR-DTG profiles of SBA-15 supported $(a, b)$ and bulk (c,d) copper and cerium oxide modifications.

Figure 9. Cyclohexanol conversion at $503 \mathrm{~K}$ over various SBA-15-supported catalysts after a pre-treatment in air at $373 \mathrm{~K}$ (a) or after reduction with hydrogen at $523 \mathrm{~K}$ for $2 \mathrm{~h}$ (b).

\section{Supplementary data:}

Figure S1. By-products distribution on copper and cerium oxide bulk (a) and SBA-15 supported (b) samples at $630 \mathrm{~K}$ and 40 min time on stream. 
Figure S2. Nitrogen physisorption isotherms of selected SBA-15 modifications.

Figure S3. Small angle XRD patterns of SBA-15 modifications.

Figure S4. FTIR spectra of parent SBA-15 and its modifications with cerium and copper oxides.

Figure S5. FTIR spectra of SBA-15 materials after ethyl acetate oxidation. 
Table 1. Nitrogen physisorption ${ }^{\mathrm{a}}$ and $\mathrm{XRD}^{\mathrm{b}}$ data for copper and cerium oxide bulk and supported on SBA-15 materials.

\begin{tabular}{lccccccc}
\hline Sample & $\begin{array}{c}\mathrm{BET} \\
\mathrm{m}^{2} / \mathrm{g}\end{array}$ & $\begin{array}{c}\mathrm{V}_{\text {mes, }} \\
\mathrm{cm}^{3} / \mathrm{g}\end{array}$ & $\begin{array}{c}\mathrm{D} \text { pores, } \\
\mathrm{nm}\end{array}$ & $\begin{array}{c}\mathrm{V}_{\text {mic }} \\
\mathrm{cm}^{3} / \mathrm{g}\end{array}$ & $\begin{array}{c}\mathrm{CuO}, \\
\mathrm{nm}\end{array}$ & $\begin{array}{c}\mathrm{CeO}_{2}, \\
\mathrm{~nm}\end{array}$ & $\begin{array}{c}\mathrm{a}_{\mathrm{CeO} 2}, \\
\AA\end{array}$ \\
\hline $\mathrm{SBA}-15$ & 807 & 0.99 & 5.9 & 0.12 & & & \\
$\mathrm{Cu} / \mathrm{SBA}-15$ & 678 & 0.84 & 5.8 & 0.08 & 43.8 & & \\
4Cu2Ce/SBA-15 & 690 & 0.84 & 5.7 & 0.08 & 49.2 & & \\
3Cu3Ce/SBA-15 & 692 & 0.82 & 5.6 & 0.08 & 19.1 & & \\
2Cu4Ce/SBA-15 & 626 & 0.76 & 5.4 & 0.06 & & & \\
$\mathrm{Ce} /$ SBA-15 & 703 & 0.81 & 5.5 & 0.08 & & 3.0 & 5.413 \\
& & & & & & & \\
$\mathrm{CuO}$ & 4 & & & & 35.6 & & \\
4Cu2Ce & 55 & & & & 29.5 & 6.4 & 5.423 \\
2Cu4Ce & 35 & & & & 21.9 & 9.1 & 5.428 \\
$\mathrm{CeO} 2$ & 89 & & & & & 10.0 & 5.416 \\
\hline
\end{tabular}

a) BET surface areas, pore volume $\left(\mathrm{V}_{\text {mes }}\right)$, pore diameter $\left(\mathrm{D}_{\text {pores }}\right)$, micropore volume $\left(\mathrm{V}_{\text {mic }}\right)$.

b) phases, crystallite size and unit cell parameters of ceria $\left(\mathrm{a}_{\mathrm{CeO} 2}\right)$ calculated from XRD. 
Table 2. XPS data for selected copper oxide modified SBA-15.

\begin{tabular}{lccccc}
\hline \multicolumn{5}{c}{ Metal Surface } \\
Sample & $\begin{array}{c}\mathrm{Cu} \text { concentration } \\
\text { at } \%\end{array}$ & $\begin{array}{c}\mathrm{Ce}, \\
\text { at } \%\end{array}$ & $\begin{array}{c}\mathrm{Si} \% \\
\text { at } \%\end{array}$ & $\mathrm{Cu} / \mathrm{Si}^{*} * 10^{3}$ & $\mathrm{Ce} / \mathrm{Si}^{*} 10^{3}$ \\
\hline $\mathrm{Cu} / \mathrm{SBA}-15$ & 0.5 & - & 36.3 & 13.7 & \\
4Cu2Ce/ SBA-15 & 0.9 & 0.3 & 35.9 & 25.1 & 8.4 \\
2Cu4Ce/ SBA-15 & 0.7 & 0.5 & 37.5 & 18.7 & 13.3 \\
$\mathrm{Ce} / \mathrm{SBA}-15$ & - & 0.5 & 36.7 & - & 13.6 \\
\hline
\end{tabular}


Table 3. TPR data for copper and cerium oxide modifications.

\begin{tabular}{llllll}
\hline Sample & $\mathrm{T}_{\max }(\mathrm{K})^{(\mathrm{a})}$ & $\mathrm{T}_{\text {ini }}(\mathrm{K})^{(\mathrm{b})}$ & $\begin{array}{l}\mathrm{WL}(\mathrm{mg}) \\
(\mathrm{c})\end{array}$ & $\begin{array}{l}\text { Theoretic } \\
\text { WL }(\mathrm{mg})\end{array}$ & $\begin{array}{l}\text { Reduction } \\
\text { degree, } \%\end{array}$ \\
\hline $\mathrm{CuO}$ & 471 & 433 & 7.85 & 8.05 & 98 \\
$4 \mathrm{Cu} 2 \mathrm{Ce}$ & 456 & 369 & 3.78 & 5.38 & 63 \\
$2 \mathrm{Cu} 4 \mathrm{Ce}$ & 480 & 432 & 1.75 & 3.92 & 45 \\
$\mathrm{CeO}_{2}$ & - & 660 & 0.26 & 1.86 & 14 \\
& & & & & \\
$\mathrm{Cu} / \mathrm{SBA}-15$ & 474 & 449 & 0.51 & 0.60 & 85 \\
$4 \mathrm{Cu} 2 \mathrm{Ce} / \mathrm{SBA}-15$ & 466 & 364 & 0.35 & 0.45 & 78 \\
3Cu3Ce/SBA-15 & 457 & 377 & 0.35 & 0.37 & 95 \\
2Cu4Ce/SBA-15 & 460 & 377 & 0.23 & 0.29 & 79 \\
$\mathrm{Ce} / \mathrm{SBA}-15$ & - & 659 & 0.05 & 0.14 & 35 \\
\hline
\end{tabular}

a) $\mathrm{T}_{\max }$-temperature of maximum weight loss.

b) $\mathrm{T}_{\mathrm{ini}}$-starting temperature of reduction process.

c) WL-weight loss in the $375-770 \mathrm{~K}$ region.

d) Theoretic calculations are based on $\mathrm{Cu}^{2+} \rightarrow \mathrm{Cu}^{0}$ and $\mathrm{Ce}^{4+} \rightarrow \mathrm{Ce}^{3+}$ transitions. 

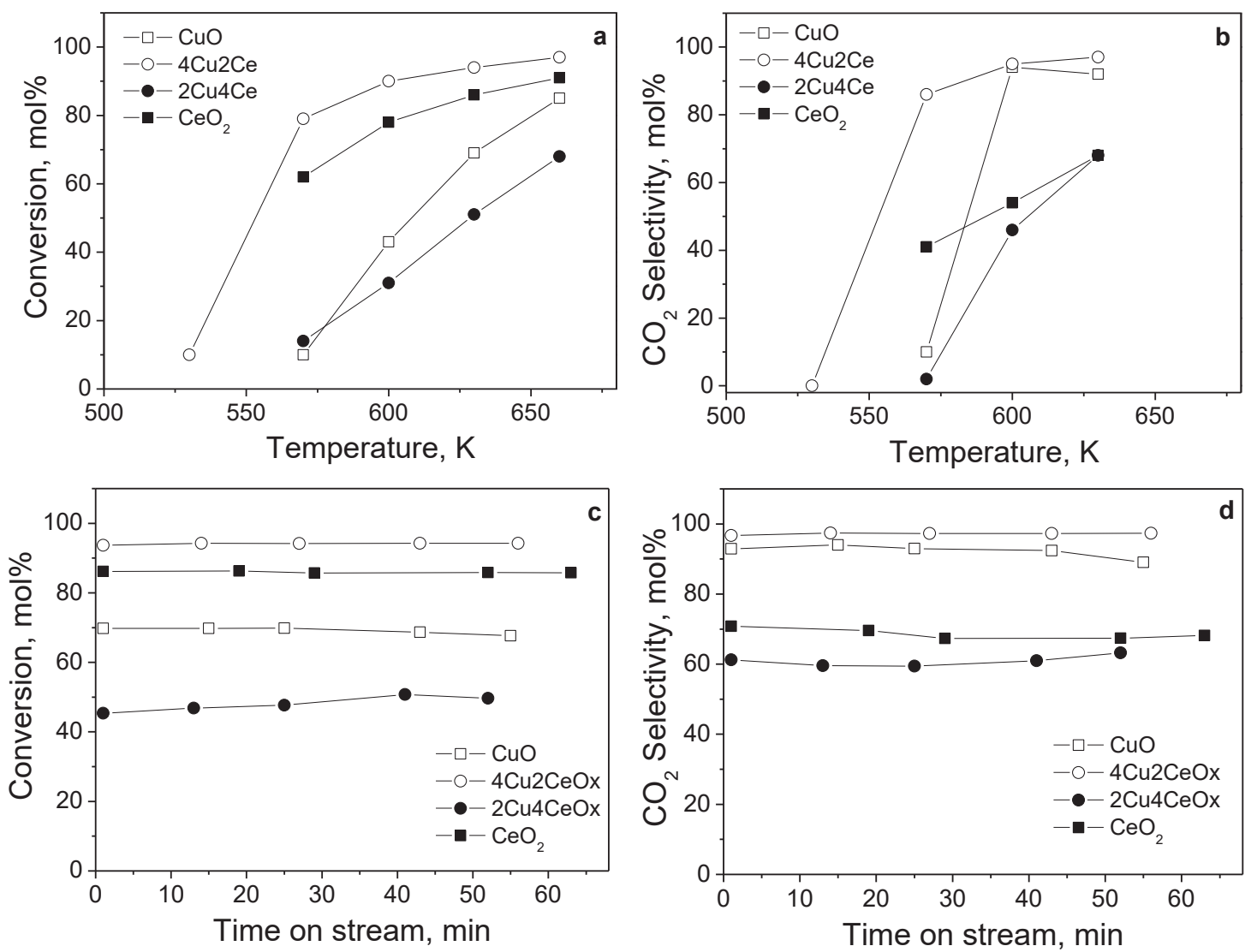

Figure 1. Evolution of ethyl acetate conversion (a, c) and $\mathrm{CO}_{2}$ selectivity (b, d) with reaction temperature (up) or with time on stream at $630 \mathrm{~K}$ (down) for various bulk modifications. 

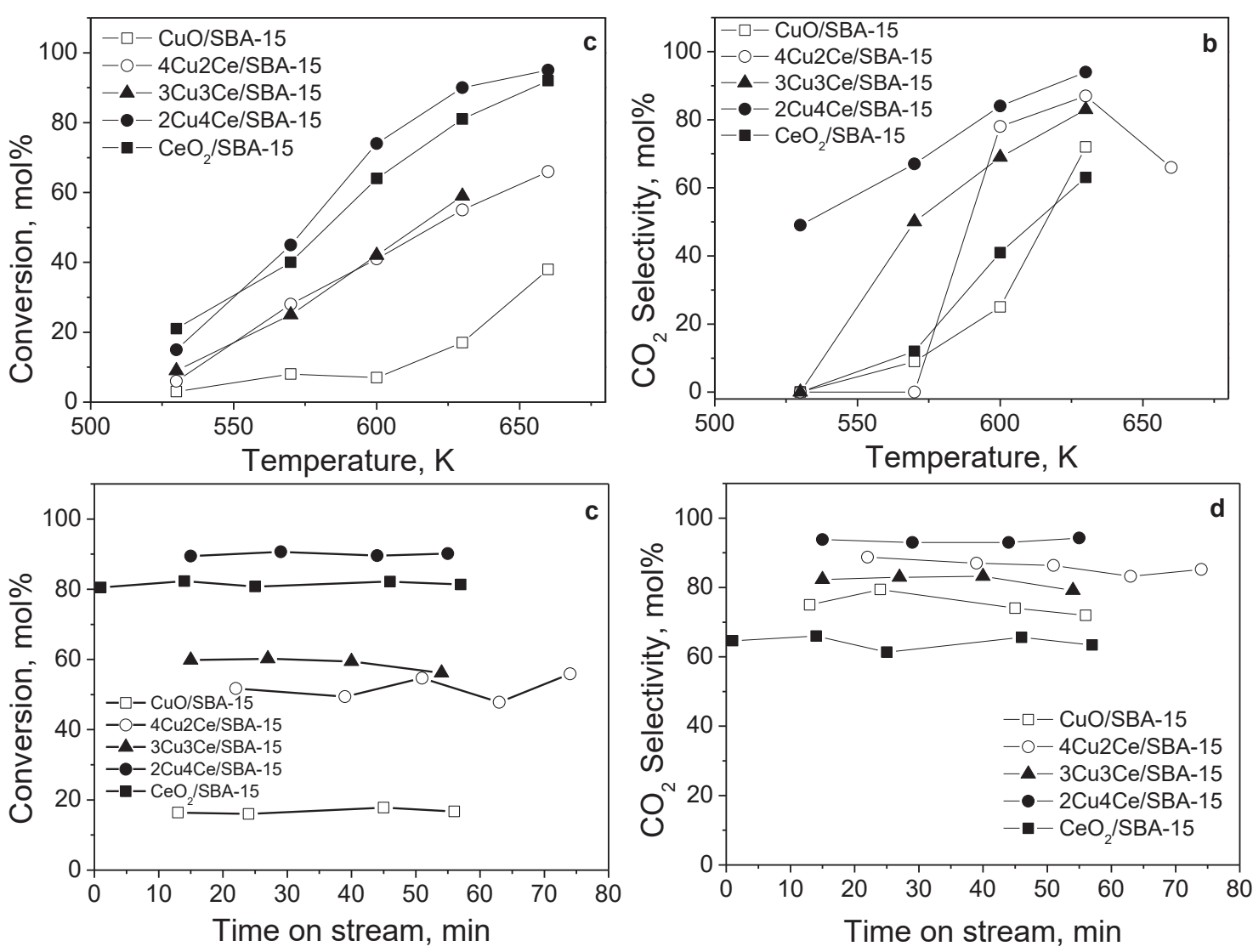

Figure 2. Evolution of ethyl acetate conversion (a and c) and $\mathrm{CO}_{2}$ selectivity (b and d) with temperature (up) and with time on stream at $630 \mathrm{~K}$ (down) for various SBA-15 modifications. 

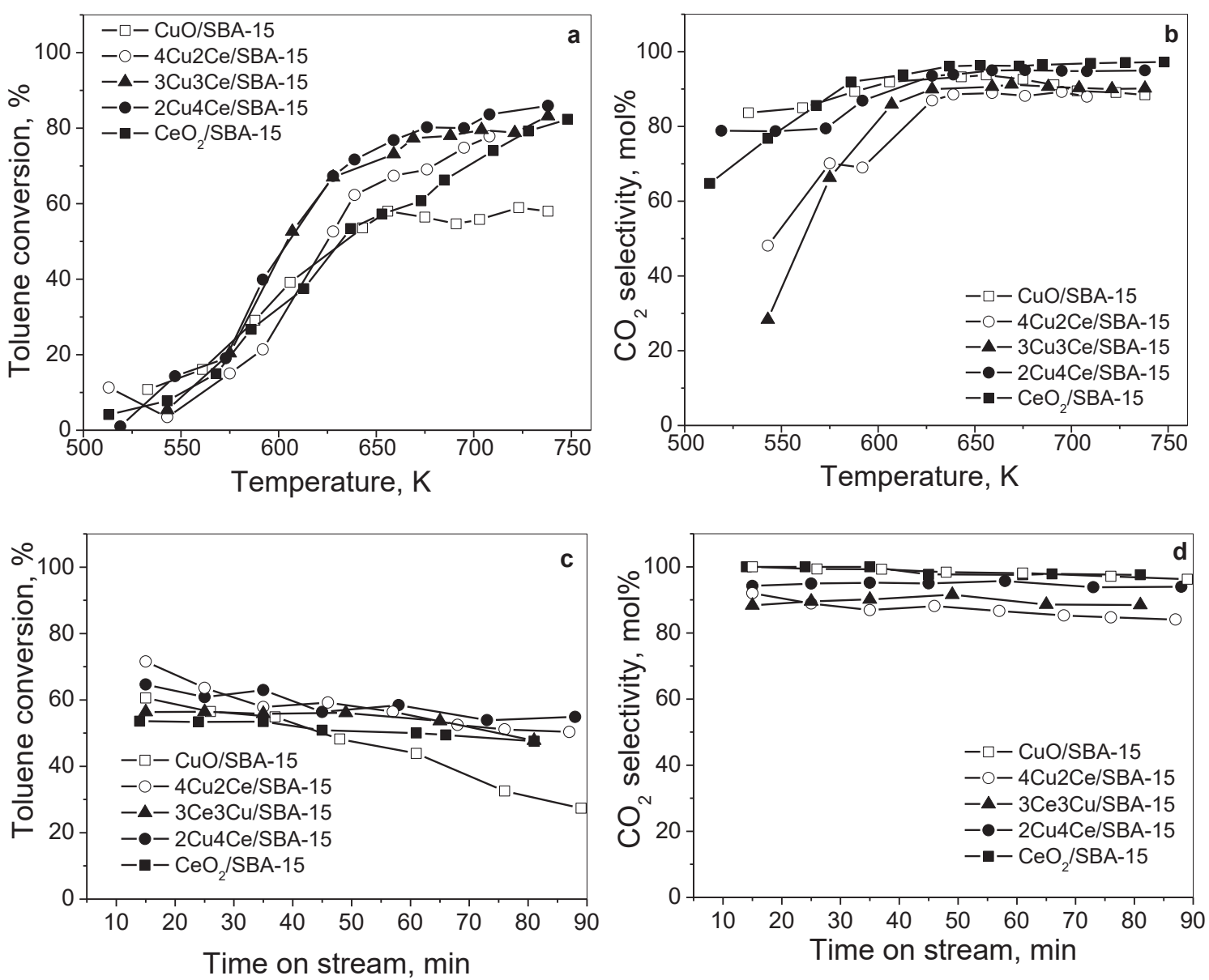

Figure 3. Evolution of toluene conversion $(\mathrm{a}, \mathrm{c})$ and $\mathrm{CO}_{2}$ selectivity $(\mathrm{b}$, d) with reaction temperature (up) or with time on stream at $630 \mathrm{~K}$ (down) for various SBA-15 modifications. 

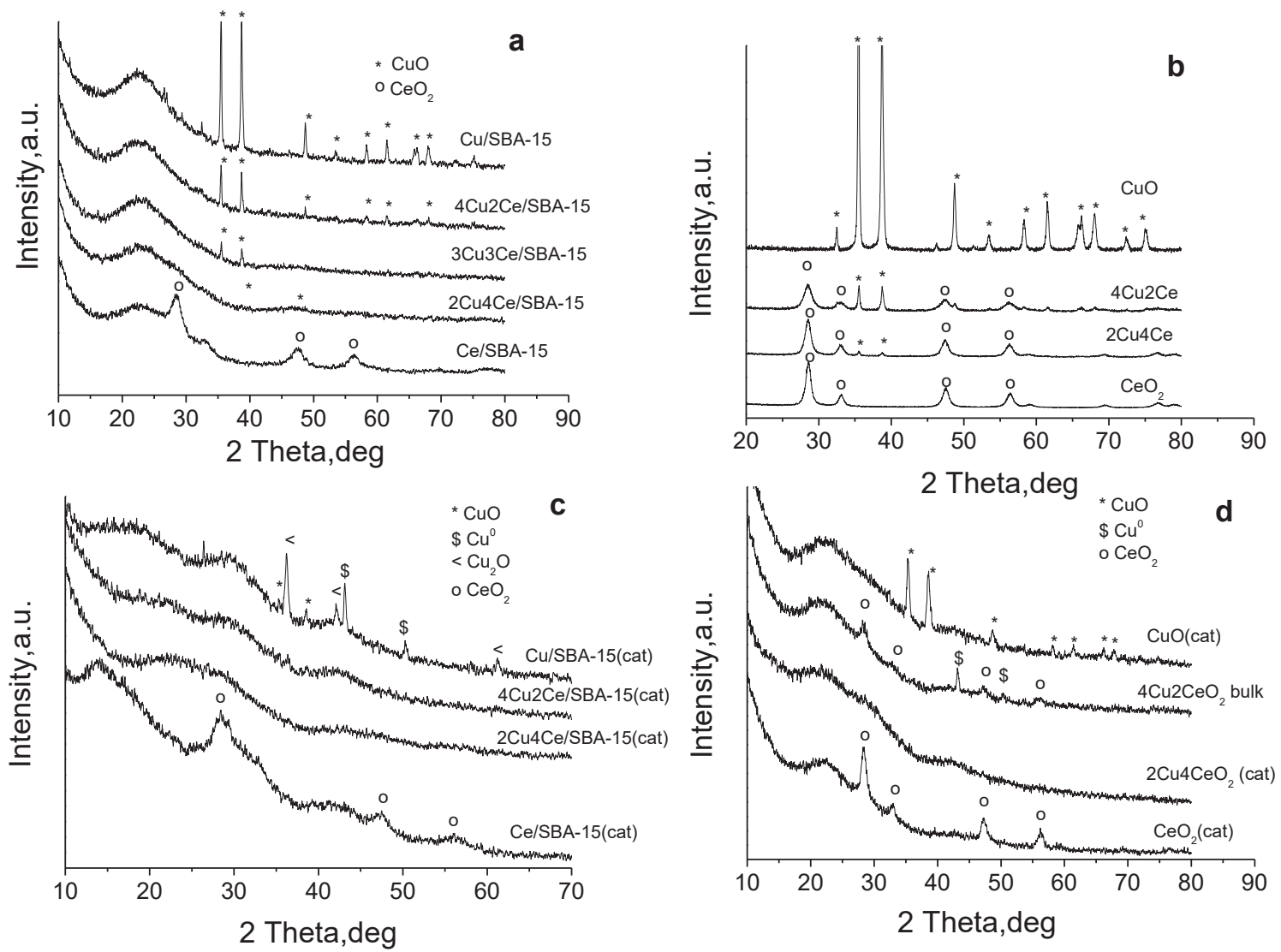

Figure 4. XRD patterns of SBA-15 modifications and bulk material before $(\mathrm{a}, \mathrm{b})$ and after catalytic test in ethyl acetate oxidation $(c, d)$. 

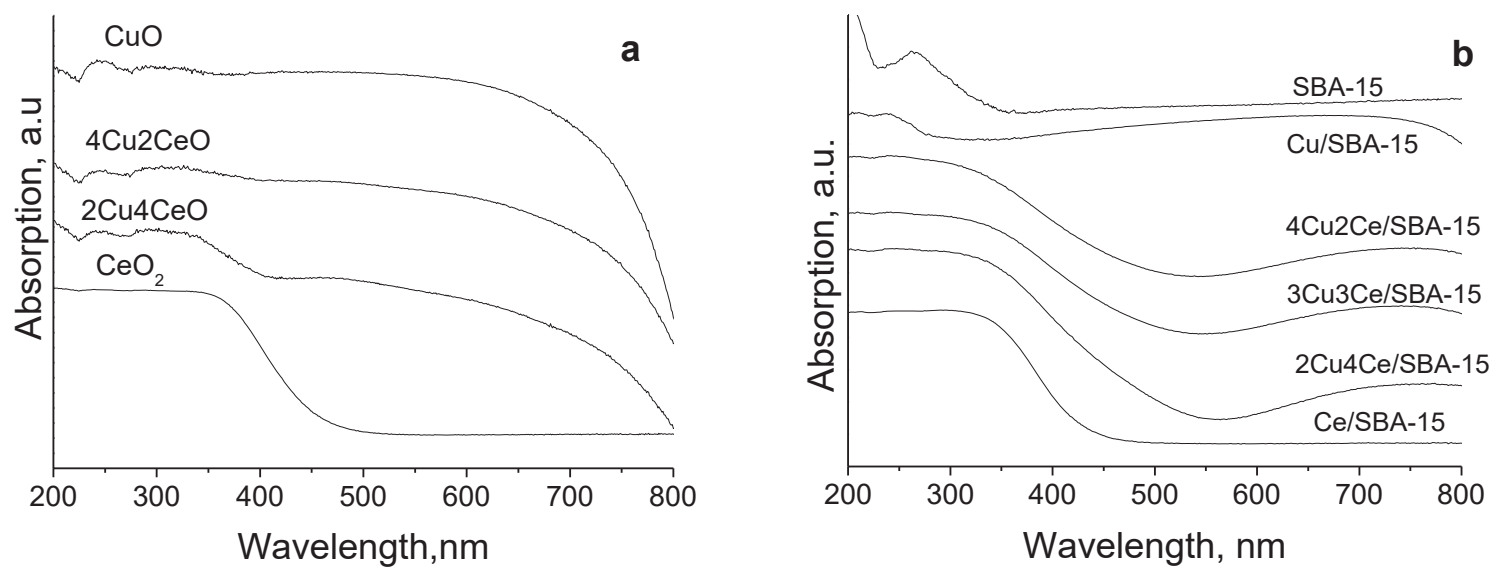

Figure 5. UV- Vis spectra for copper and cerium oxide bulk (a) and supported on SBA-15 silica (b) materials. 

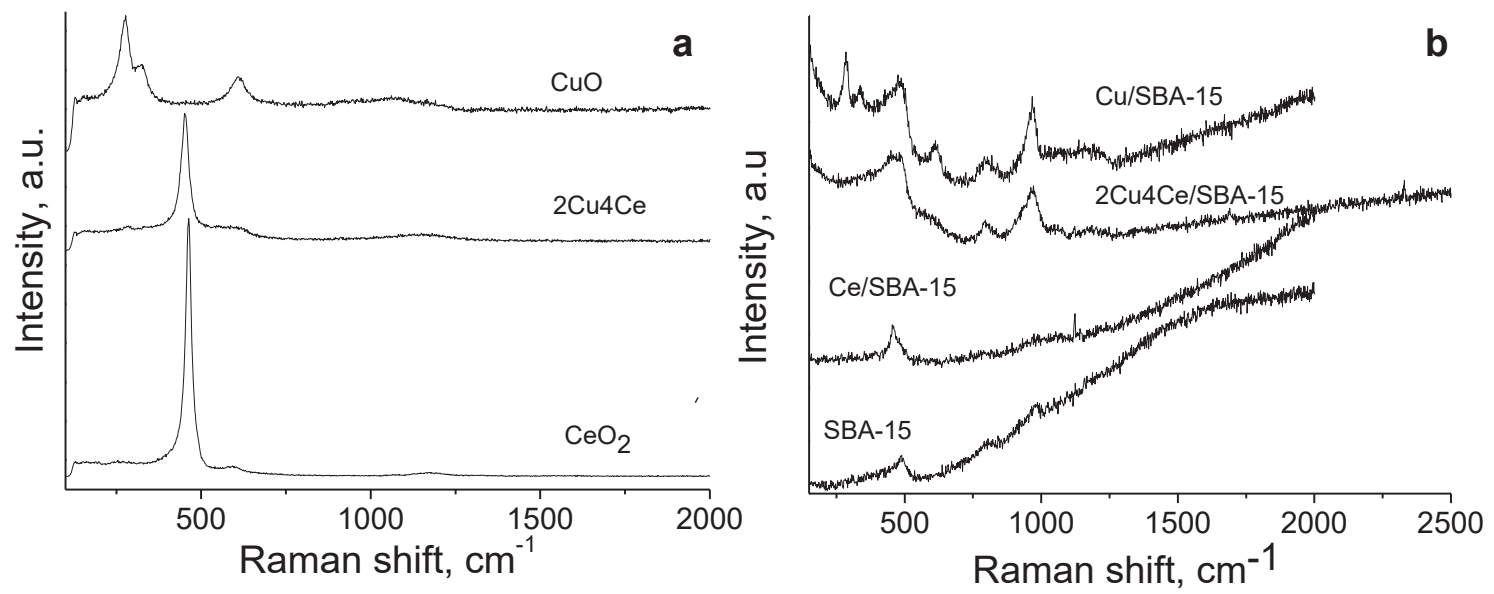

Figure 6. Raman spectra of selected copper and cerium oxide bulk (a) and SBA-15 supported (b) materials. 

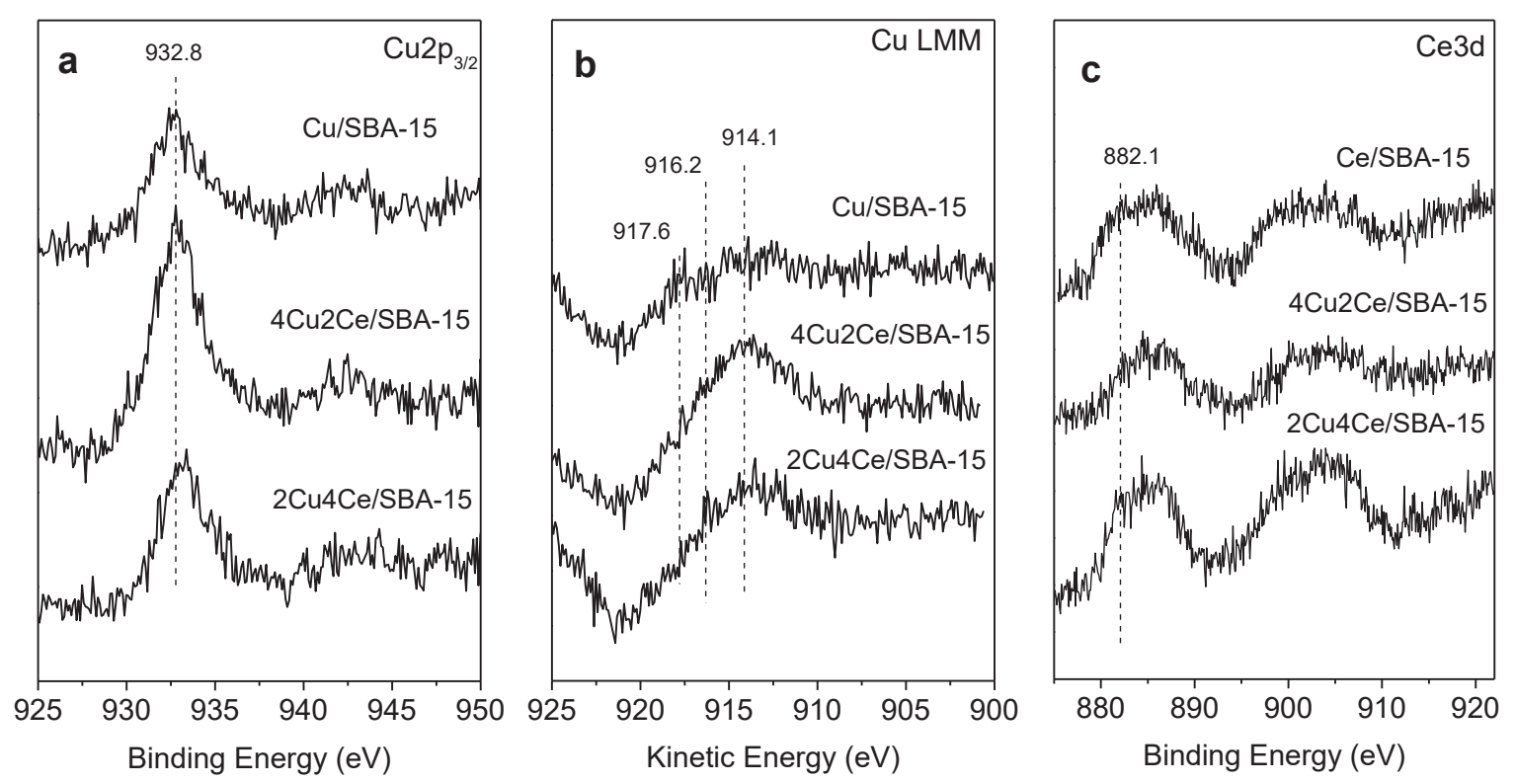

Figure 7. $\mathrm{Cu} 2 \mathrm{p}_{3 / 2}$ (a), CuLMM (b) and Ce3d (c) XPS spectra of selected copper and cerium oxide modified SBA-15. 

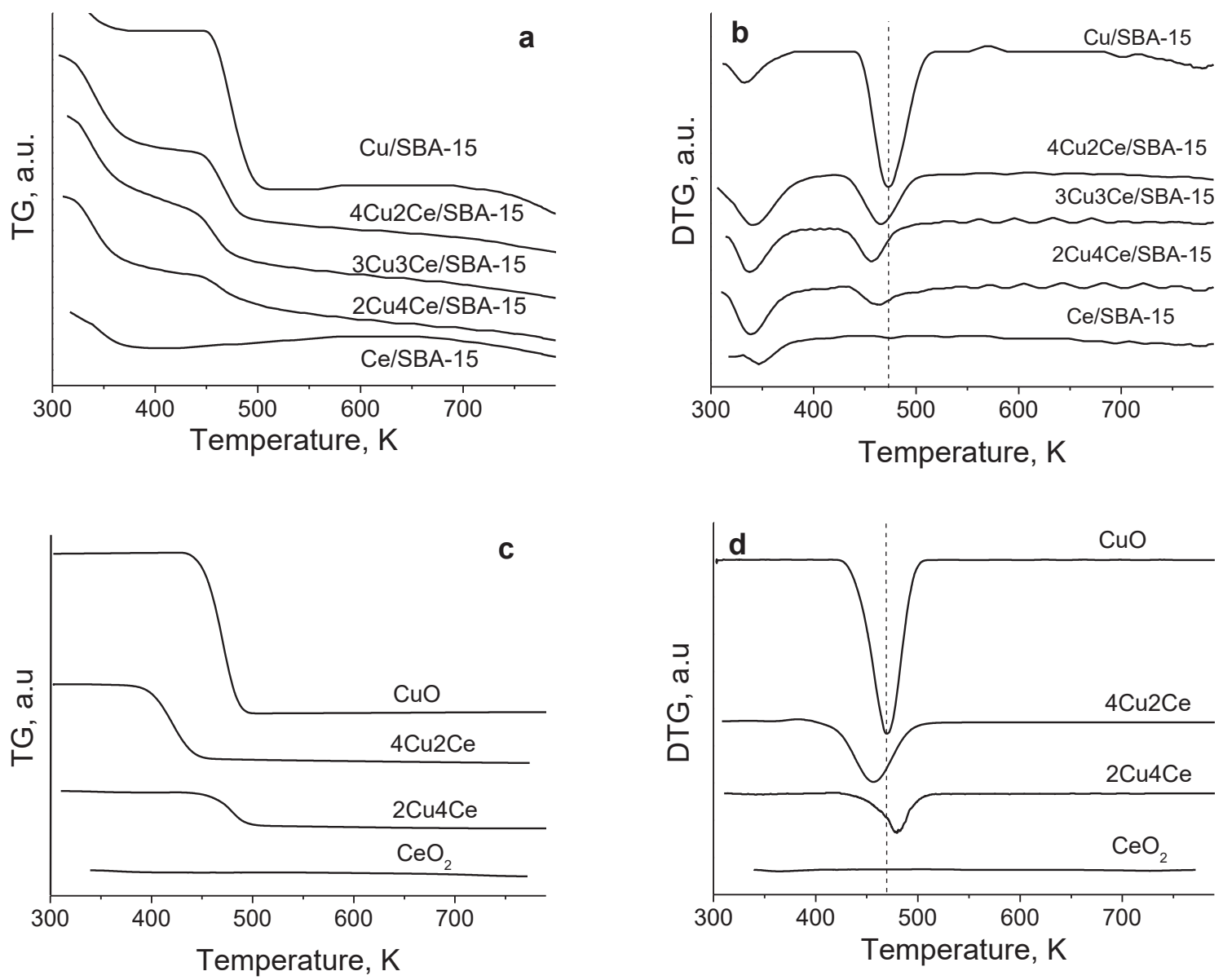

Figure 8. TPR-TG and TPR-DTG profiles of SBA-15 supported $(a, b)$ and bulk $(c, d)$ copper and cerium oxide modifications. 

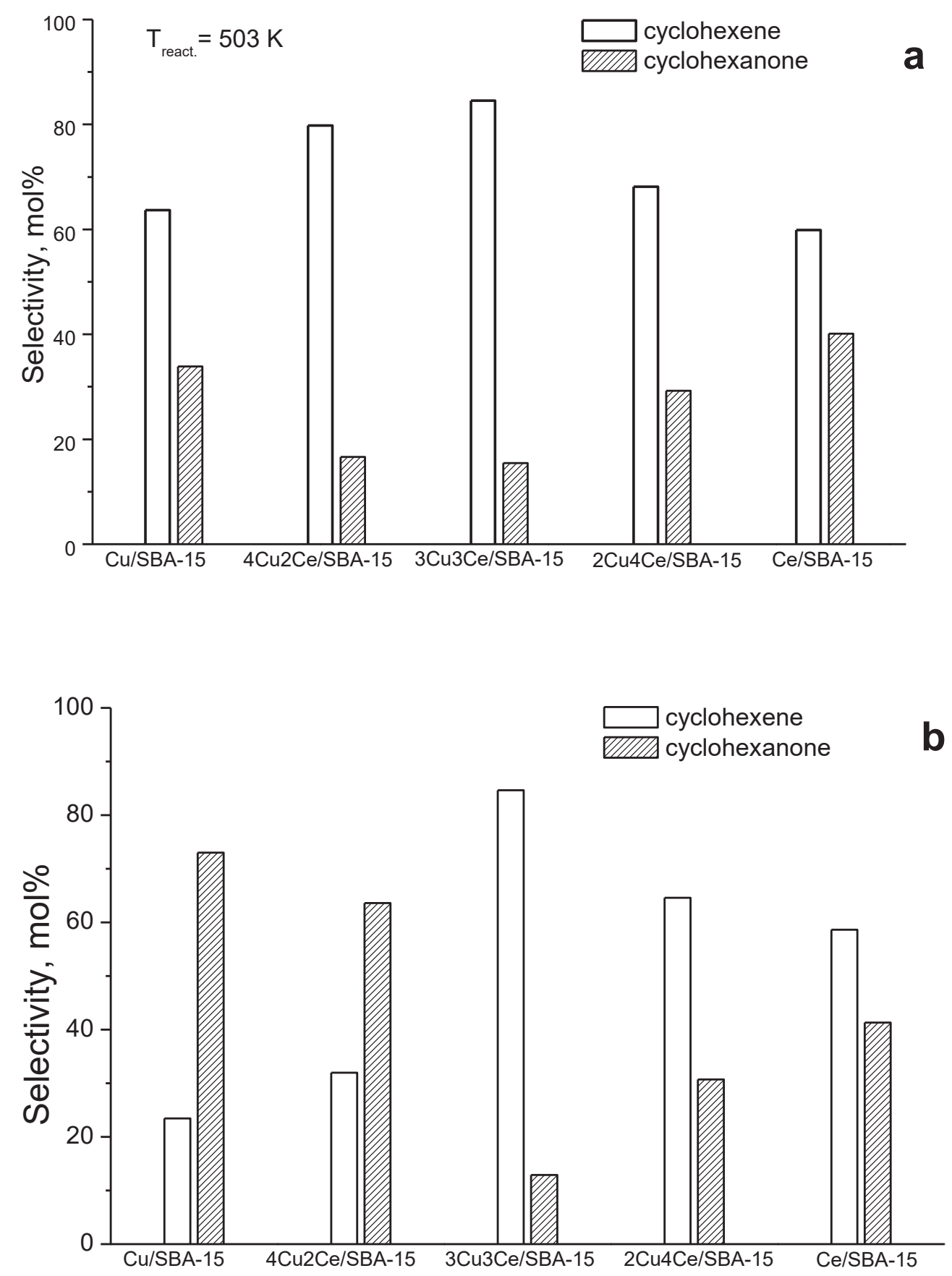

Figure 9. Cyclohexanol conversion at $503 \mathrm{~K}$ over various SBA-15-supported catalysts after a pre-treatment in air at $373 \mathrm{~K}$ (a) or after reduction with hydrogen at $523 \mathrm{~K}$ for $2 \mathrm{~h}$ (b). 